\title{
ĐCheck List
}

\section{First report on the amphibians and reptiles of a remote mountain, Gunung Tebu in northeastern Peninsular Malaysia}

\author{
Alex X. Sumarli1 ${ }^{1 *}$, L. Lee Grismer ${ }^{1}$, Shahrul Anuar ${ }^{2}$, Mohd Abdul Muin $^{2}$ and Evan S.H. Quah \\ 1 Department of Biology, La Sierra University, 4500 Riverwalk Parkway, Riverside, CA 92515 USA \\ 2 School of Biological Sciences, Universiti Sains Malaysia, 11800 Minden, Penang, Malaysia \\ * Corresponding author. E-mail: sumarli.alex@gmail.com
}

\begin{abstract}
This is the first herpetological survey and checklist of the Mount Tebu (Gunung Tebu) region including the upland areas of Gunung Tebu, the surrounding lowlands of Hutan Lipur Lata Belatan, and the nearby lowland region of Hutan Lipur Lata Tembaka in Terrengganu, northeastern Peninsular Malaysia. Expanding upon the only previous herpetological survey in this region from Gunung Lawit (Dring 1979), we record a total of 106 species including 43 species previously unknown from this portion of Peninsular Malaysia.
\end{abstract}

Key words: Southeast Asia, Banjaran Timur, conservation

Peninsular Malaysia is a topographically complex region bearing three major mountain systems: the Banjaran (mountain range) Bintang range in the West, the Banjaran Titiwangsa range in central Peninsular Malaysia, and the Banjaran Timur range in the northeast. The latter is a sculpted series of jagged, isolated, mountainous corridors, and is the second largest upland system in Peninsular Malaysia. These mountains are composed of an array of imbricating peaks, hills, and plateaus dissected by several rivers and streams.

Peninsular Malaysia's fragmented upland systems have long been known to harbor a significant amount of herpetofaunal diversity and endemism (e.g., Boulenger 1900a, 190ob, 1903, 1908; Chan et al. 2009, 2014; Das et al. 2004; Das and Norsham 2003; Dring 1979; Flower 1896, 1899; Grandison 1972; Grismer 2006a, 2007, 2008a, 2011a, 2011b; Grismer and Pan, 2008; Grismer et al. 2006d, 2008a, 2009a, 2009b, 2010; Hallerman and McGuire 2001; Laidlaw 1900, 1901a, 1901b; Leong and Lim 2003; Lim et al. 2002; Matsui and Ibrahim, 2006; McLeod and Norhyati, 2007; Norsham and Lim, 2002; Sanders et al. 2004; Sly 1976; Smedley 1931; Smith 1922, 1935; Vogel et al. 2004; Wood et al. 2008, 2009), yet few publications have focused on the herpetofauna of upland regions until recently (Grismer 2006b, 2006c,
2007, 2008b; Grismer et al. 2006e, 2008a, 2009a, 2009b, 2010, 2011, 2012, 2014, in press; Chan et al. 2009, 2010, 2014; Johnson et al. 2012; Loredo et al. 2013). A survey and literature summary of the herpetofauna of the Banjaran Bintang Mountains in western Peninsular Malaysia (Grismer et al. 2010) list a total of 107 species. Herpetological surveys in northeastern Peninsular Malaysia have been virtually non-existent since Dring's (1979) survey from Gunung (mountain) Lawit, Terrenganu where he identified 77 species and described two new species of geckos, Cnemaspis argus and Cyrtodactlus elok. Gunung Lawit $(1,519 \mathrm{~m})$ is the highest peak in the northern region of the Banjaran Timur range and is situated between Ulu Terrenganu and Ulu Besut (Figure 1). There have been no herpetological studies in the uplands of Gunung Lawit and its surrounding

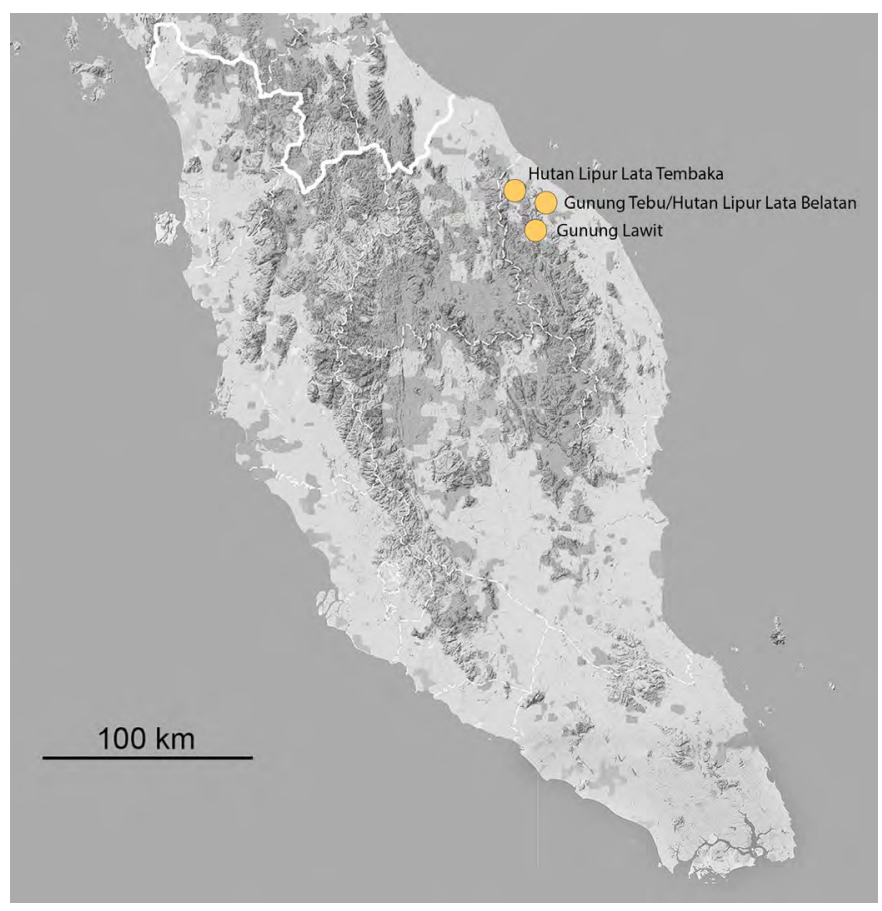

Figure 1. Map of Peninsular Malaysia showing Gunung Tebu/Hutan Lipur Lata Belatan, Gunung Lawit and Hutan Lipur Lata Tembaka. 
lowlands since Dring (1979), although a failed attempt to summit Gunung Lawit in September of 2012 resulted in additional records from the lowland regions and are presented below. During recent surveys we did summit an adjacent mountain, Gunung Tebu just $10 \mathrm{~km}$ to the north of Gunung Lawit in the same mountain range and were able to sample extensively the herpetofauna of this area.

The following survey is a compilation of two expeditions to Gunung Tebu and the surrounding lowlands of Hutan Lipur Lata Belaltan and the lowland regions surrounding the Hutan Lipur Lata Tembaka (Figure 1) and represents the first account of the herpetofauna from these areas. A composite checklist based on this study and Dring's (1979) records from Gunung Lawit are presented in Table 1.

Gunung Tebu is located within the northeastern section of the Banjaran Timur and reaches 1,039 m at its summit (Figure 1). Hutan Lipur Lata Belatan is situated at the base of Gunung Tebu and covers an area of approximately 20 hectares. It is approximately $28 \mathrm{~km}$ northeast from Hutan Lipur Lata Tembaka, another lowland locality at the base of an adjacent mountain range (Figure 1). We began surveys at Hutan Lipur Lata Belatan in anthropomorphic areas and along a slow flowing river (Sungai Belatan) shaded by riparian forest. On the Gunung Tebu trail, most collections were made between approximately $600-750 \mathrm{~m}$, around the vicinity of Punca Air at $610 \mathrm{~m}$, and slightly above $800 \mathrm{~m}$. Punca Air $(610 \mathrm{~m})$ was composed of primary hill dipterocarp forest and had a stream approximately $60 \mathrm{~m}$ below our camp that coursed through riverine habitat.

The collection sites were:

- Hutan Lipur Lata Tembaka $\left(05^{\circ} 35^{\prime} 15.16^{\prime \prime} \mathrm{N}, 102^{\circ} 27^{\prime}\right.$ 07.56" E; $57 \mathrm{~m}$ ) - Lata Tembaka is a lowland site on a parallel mountain range across a small flood plain that separates it from the Gunung Lawit and Gunung Tebu range (Figure 1). The survey area ranges along a wide river with pools and rocky, cascades coursing through lowland dipterocarp and riparian forest (Figures 2 and 3 ).

- Hutan Lipur Lata Belatan $\left(05^{\circ} 38^{\prime} 20.61^{\prime \prime} \mathrm{N}, 102^{\circ} 35^{\prime}\right.$ 16.81" E; $42 \mathrm{~m}$ ) - Lata Belatan is a wide, flat valley at the base of Gunung Tebu coursed by fast-flowing cascades and waterfalls collecting at several large pools. The vegetation is characterized by lowland riparian forest and low hill dipterocarp forest. Shallow pools, streams, and damp granite rocks along the riverbank provided ample microhabitat for frogs. Patches of leaf litter and thick, low-lying vegetation separate the trail from the stream. Several lizard species were collected from large to medium trees in primary and disturbed forest and from pondok (hut) walls (Figures 4-6).

- Punca Air $\left(05^{\circ} 36.11^{\prime} \mathrm{N}, 102^{\circ} 36.19^{\prime} \mathrm{E} ; 610 \mathrm{~m}\right)$ - Punca

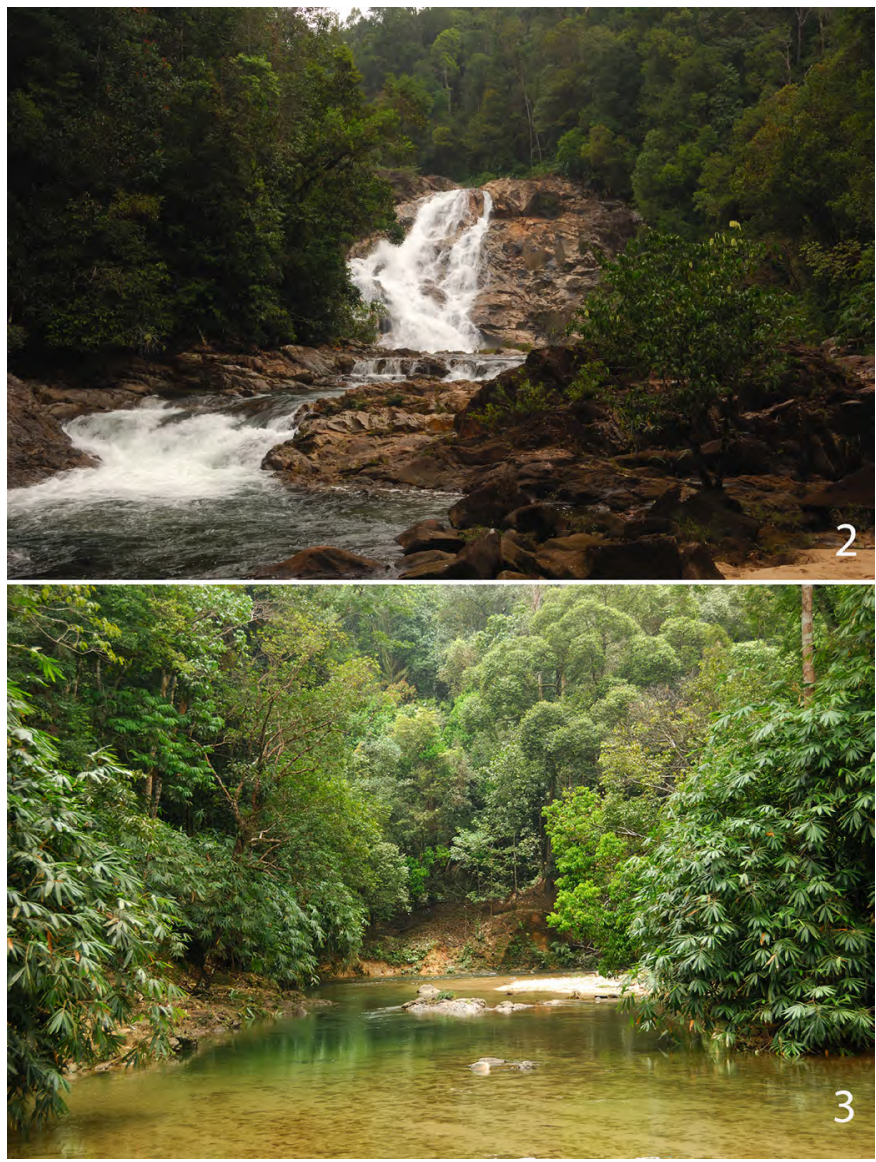

Figures 2 and 3. Lata Tembaka habitat. 2: Waterfall and cascades in lowland riparian/dipterocarp forest at $100 \mathrm{~m}$; 3: Lowland riparian forest at $150 \mathrm{~m}$.

Air located on Gunung Tebu is composed of primary hill dipterocarp forest and riverine habitat. Directly downhill from a camping outpost, it is coursed by a wide, slow flowing stream. Mossy, granite crevices and overhanging vegetation along the riverbank provide numerous microhabitats for several species (Figure 7) Collections around the campground were made from large trees and low vegetation. Above Punca Air to the summit, collections were made in primary hill dipterocarp forest (Figure 8).

- Summit of Gunung Tebu ( $05^{\circ} 35^{\prime} 35.47^{\prime \prime} \mathrm{N}, 102^{\circ} 36^{\prime} 45.63^{\prime \prime}$ $\mathrm{E} ; 1,039 \mathrm{~m})$ - The vegetation leading to the summit of Gunung Tebu is upper mountain forest and cloud forest. Low vegetation, decaying logs, roots, and trees provided suitable microhabitat for several species. Above 1,000 $\mathrm{m}$, the summit is marked with stunted trees and granite boulders (Figure 9). On 2 September 2012, the weather was misty for most of the day and rained heavily at night.

Surveys of the Gunung Tebu region occurred from 9-11 July 2012, 31 August to 3 September 2012, 9 September 2012, and 30 June to 3 July 2013. On 3 and 13 March 2008, 2 and 3 July 2010, 5-7 September 2010, and 24 and 25 June 2012, we surveyed the Hutan Lipur Lata Tembaka. All individuals were caught by hand or with 
the aid of blowpipes. Photos of representative samples of each species were taken prior to euthanization. Liver tissue samples were subsequently taken from each individual and stored in $100 \%$ ethanol. Specimens were fixed in $10 \%$ formalin and later transferred to $70 \%$ ethanol.

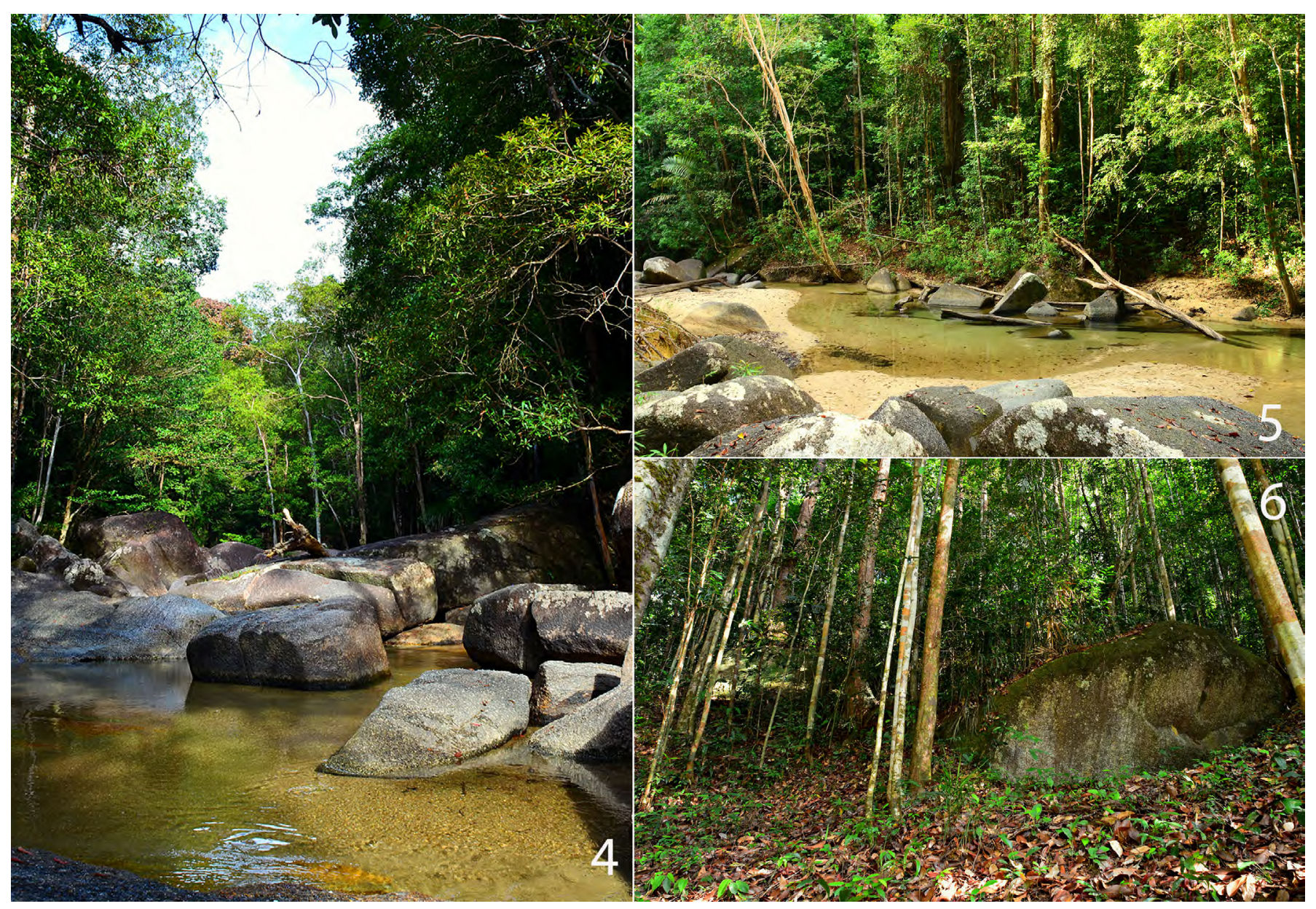

Figures 4-6. Lata Belatan habitat. 4 and 5: Lowland riparian forest, 6: Low hill dipterocarp forest.

Table 1. Checklist of the herpetofauna from Gunung Lawit, Gunung Tebu, and the lowlands of Lata Belatan, and Lata Tembaka.

\begin{tabular}{lccc}
\hline Taxa & $\begin{array}{c}\text { Gunung } \\
\text { Lawit }\end{array}$ & Gunung Tebu & Lata Belatan \\
\hline CAECILIANS & & & \\
Icthyophidae & & & \\
IChthyophis sp. & $\mathrm{X}$ & - \\
\hline
\end{tabular}

\section{FROGS}

Bufonidae

Ansonia latifii Wood, Grismer, Norhayati \& Juliana, 2008

Ansonia lumut Chan, Wood, Anuar, Muin, Quah Sumarli \& Grismer, 2014

Duttaphrynus melanostictus (Schneider, 1799)

Ingerophrynus parvus (Boulenger, 1887)

Ingerophrynus quadriporcatus (Boulenger, 1887)

Leptophryne borbonica (Tschudi, 1838)

Pedostibes hosii (Boulenger, 1892)

Phrynoides aspera (Gravenhorst, 1829)

\section{Dicroglossadae}

Fejervarya limnocharis (Boie, 1835)

Limnonectes blythii (Blyth, 1856)

Limnonectes kuhlii (Duméril \& Bibron, 1841)

Limnonectes laticeps (Boulenger, 1882)

Limnonectes plicatellus (Stoliczka, 1873)

\begin{tabular}{llll}
$\mathrm{X}$ & - & - & $\mathrm{X}$ \\
$\mathrm{X}$ & $\mathrm{X}$ & - & - \\
- & - & $\mathrm{X}$ & - \\
$\mathrm{X}$ & - & $\mathrm{X}$ & $\mathrm{X}$ \\
$\mathrm{X}$ & - & - & - \\
$\mathrm{X}$ & - & - & - \\
$\mathrm{X}$ & - & - & - \\
$\mathrm{X}$ & - & $\mathrm{X}$ & $\mathrm{X}$ \\
$\mathrm{X}$ & & & - \\
$\mathrm{X}$ & - & $\mathrm{X}$ & $\mathrm{X}$ \\
$\mathrm{X}$ & $\mathrm{X}$ & - & - \\
$\mathrm{X}$ & $\mathrm{X}$ & - & $\mathrm{X}$ \\
$\mathrm{X}$ & $\mathrm{X}$ & $\mathrm{X}$ & - \\
\hline & - & - & Continued
\end{tabular}




\begin{tabular}{|c|c|c|c|c|}
\hline Taxa & $\begin{array}{c}\text { Gunung } \\
\text { Lawit }\end{array}$ & Gunung Tebu & Lata Belatan & Lata Tembaka \\
\hline Limnomectes paramacrodon (Inger, 1966) & $x$ & - & - & - \\
\hline Limnonectes tweediei (Smith, 1935) & $x$ & - & - & - \\
\hline Occidozyga martensii (Peters, 1867) & $x$ & - & $x$ & $x$ \\
\hline Occidozyga sumatrana (Peters, 1877) & $\mathrm{x}$ & - & - & - \\
\hline Taylorana hascheanus (Stolickza, 1870) & - & $x$ & - & - \\
\hline \multicolumn{5}{|l|}{ Microhylidae } \\
\hline Kalophrynus pleurostigma (Tschudi, 1838) & $x$ & - & - & $\mathrm{x}$ \\
\hline Microhyla berdmorei (Blyth, 1856) & $x$ & - & - & $x$ \\
\hline Microhyla butlerli Boulenger, 1900 & $\mathrm{x}$ & - & - & - \\
\hline Microhyla heymonsi (Vogt, 1911) & $x$ & - & $x$ & - \\
\hline Microhyla fissipes Matsui, 2005 & - & - & $x$ & - \\
\hline Microhyla mantheyi Das, Yaakob \& Sukumaran, 2007 & $\mathrm{x}$ & - & - & - \\
\hline Microhyla supercilaris (Parker, 1928) & - & - & $x$ & - \\
\hline Metaphrynella pollicaris (Boulenger, 1890) & $x$ & $x$ & & - \\
\hline \multicolumn{5}{|l|}{ Megophryidae } \\
\hline Leptobrachium hendricksoni (Tschudi, 1838) & $x$ & - & $x$ & $x$ \\
\hline Leptolalax sp. & $\mathrm{x}$ & $\mathrm{x}$ & - & - \\
\hline Megophrys nasuta (Schlegeal, 1858) & $\mathrm{x}$ & - & $\mathrm{x}$ & - \\
\hline Xenophrys aceras (Boulenger, 1903) & $x$ & $x$ & - & - \\
\hline \multicolumn{5}{|l|}{ Ranidae } \\
\hline Amalops larutensis (Boulenger, 1899) & $x$ & $x$ & $x$ & $x$ \\
\hline Hylarana labialis (Boulenger, 1887) & $\mathrm{x}$ & - & $x$ & - \\
\hline Hylarana laterimaculata (Barbour \& Noble, 1916) & $\mathrm{x}$ & - & $\mathrm{x}$ & - \\
\hline Hylarana glandulosa (Boulenger, 1882) & - & - & $x$ & - \\
\hline Hylaran luctuosa (Peters, 1871) & $\mathrm{x}$ & - & - & - \\
\hline Hylarana picturata (Boulenger, 1920) & $x$ & - & - & $x$ \\
\hline Odorrana hosii (Boulenger, 1891) & $\mathrm{x}$ & - & $\mathrm{x}$ & $x$ \\
\hline \multicolumn{5}{|l|}{ Rhacophoridae } \\
\hline Kurixalus appendicualtus (Günther, 1858) & $x$ & - & - & $x$ \\
\hline Philautus petersi (Boulenger, 1900) & - & $x$ & - & - \\
\hline Philautus vermiculatus (Boulenger, 1900) & $\mathrm{x}$ & $\mathrm{x}$ & - & - \\
\hline Polypedates colleti (Boulenger, 1890) & $\mathrm{x}$ & - & - & - \\
\hline Polypedates leucomystax (Gravenhorst, 1829) & $x$ & $x$ & $x$ & $x$ \\
\hline Polypedates macrotis (Boulenger, 1891) & $x$ & $x$ & - & $x$ \\
\hline Rhacophorus bipunctatus Ahl, 1927 & $\mathrm{x}$ & - & - & - \\
\hline Rhacophorus nigropalmatus Boulenger, 1895 & $\mathrm{x}$ & - & - & - \\
\hline Rhacophorus pardalis Günther, 1859 & $x$ & - & - & - \\
\hline Rhacophorus norhayati (Chan \& Grismer, 2010) & $\mathrm{x}$ & - & - & - \\
\hline Theloderma leprosum Tschudi, 1838 & $\mathrm{x}$ & - & - & - \\
\hline Theloderma horridum (Boulenger, 1903) & $\mathrm{x}$ & $\mathrm{x}$ & - & - \\
\hline
\end{tabular}

\begin{tabular}{|c|c|c|c|c|}
\hline \multicolumn{5}{|l|}{ LIZARDS } \\
\hline \multicolumn{5}{|l|}{ Agamidae } \\
\hline Acanthosaura armata (Hardwicke \& Gray, 1827) & $\mathrm{x}$ & - & - & - \\
\hline Aphaniotis fusca (Peters, 1864) & $\mathrm{x}$ & - & $\mathrm{x}$ & $\mathrm{x}$ \\
\hline Bronchocela cristatella (Kuhl, 1820) & $x$ & - & - & - \\
\hline Calotes emma (Gray, 1845) & - & - & - & $x$ \\
\hline Calotes versicolor (Daudin, 1802) & - & - & $\mathrm{x}$ & - \\
\hline Draco formosus (Boulenger, 1900) & $x$ & - & $x$ & $x$ \\
\hline Draco melanopogan (Boulenger, 1887) & $x$ & $x$ & $x$ & $x$ \\
\hline Draco sumatranus (Schlegel, 1844) & - & - & $\mathrm{x}$ & $x$ \\
\hline Draco quinquefasciatus (Hardwicke \& Gray, 1827) & $x$ & - & - & $x$ \\
\hline Gonocephalus abbotti (Cochran, 1922) & - & $x$ & - & - \\
\hline Gonocephalus bellii (Duméril \& Bibron, 1837) & $\mathrm{x}$ & $\mathrm{x}$ & $\mathrm{x}$ & $x$ \\
\hline Gonocephalus grandis (Gray, 1845) & $x$ & - & $x$ & - \\
\hline Gonocephalus liogaster (Günter, 1872) & $x$ & - & - & - \\
\hline Pseudocalotes dringi Hallerman \& Böhme, 2000 & $\mathrm{x}$ & - & - & - \\
\hline
\end{tabular}




\begin{tabular}{|c|c|c|c|c|}
\hline Taxa & $\begin{array}{l}\text { Gunung } \\
\text { Lawit }\end{array}$ & Gunung Tebu & Lata Belatan & Lata Tembaka \\
\hline \multicolumn{5}{|l|}{ Gekkonidae } \\
\hline Cnemaspis argus Dring, 1979 & $x$ & $x$ & $x$ & - \\
\hline Cyrtodactylus consobriunus (Peters, 1871) & $x$ & $\mathrm{x}$ & - & $X$ \\
\hline Cyrtodactylus elok Dring, 1979 & $\mathrm{x}$ & - & - & - \\
\hline Cyrtodactylus quadrivirgatus Taylor, 1962 & $x$ & $x$ & $x$ & - \\
\hline $\begin{array}{l}\text { Crytodactylus timur Grismer, Wood, Shahrul, Quah, Muin, Maketab, Chan, Sumarli, Loredo } \\
\text { \& Heinz, } 2014\end{array}$ & - & $\mathrm{x}$ & - & - \\
\hline Gehyra mutilata (Wiegmann, 1834) & $\mathrm{x}$ & $\mathrm{x}$ & $x$ & $X$ \\
\hline Gekko monarchus (Schlegel, 1836) & - & - & $x$ & - \\
\hline Gekko smithii (Gray, 1842) & - & $\mathrm{x}$ & - & - \\
\hline Hemidactylus craspedotus (Mocquard, 1890) & - & - & $x$ & - \\
\hline Hemidactylus frenatus Duméril \& Bibron, 1836 & - & - & $\mathrm{X}$ & - \\
\hline Hemidactylus platyurus (Schneider, 1792) & - & - & $x$ & - \\
\hline $\begin{array}{l}\text { Hemiphyllodactylus tehtarik Grismer, Wood, Anuar, Muin, Quah, McGuire, Brown, Tri \& Thai, } \\
2012\end{array}$ & - & $\mathrm{x}$ & - & - \\
\hline Ptychozoon kuhli (Stejneger, 1902) & - & - & $\mathrm{X}$ & - \\
\hline Ptychozoon lionotum (Annandale, 1905) & $\mathrm{x}$ & - & $x$ & $X$ \\
\hline \multicolumn{5}{|l|}{ Scincidae } \\
\hline Dasia olivacea (Gray, 1839) & - & - & $\mathrm{X}$ & $X$ \\
\hline Eutropis macularia (Blyth, 1853) & - & - & $x$ & - \\
\hline Eutropis multifasciata (Kuhl, 1820) & $\mathrm{x}$ & $x$ & $x$ & $X$ \\
\hline Lipinia vittigera (Boulenger, 1894) & - & - & $\mathrm{X}$ & - \\
\hline Sphenomorphus praesignus (Boulenger, 1900) & $\mathrm{X}$ & $\mathrm{X}$ & - & - \\
\hline \multicolumn{5}{|l|}{ Varanidae } \\
\hline Varanus nebulosus (Gray, 1831) & $\mathrm{X}$ & - & $\mathrm{X}$ & - \\
\hline \multicolumn{5}{|l|}{ SNAKES } \\
\hline Boiga drapiezii (Günther, 1863) & $\mathrm{X}$ & $\mathrm{X}$ & $\mathrm{x}$ & - \\
\hline Boiga nigriceps (Günther, 1863) & $\mathrm{X}$ & $\mathrm{x}$ & - & - \\
\hline Boiga jaspidea (Duméril , Bibron \& Duméril, 1854) & - & - & $\mathrm{x}$ & - \\
\hline Dendrelaphis cyanochloris (Wall, 1921) & - & $\mathrm{X}$ & - & - \\
\hline Dendrelaphis formosus (Tweedie, 1983) & - & - & - & $X$ \\
\hline Lycodon subcinctus (Boie, 1827) & - & - & $\mathrm{X}$ & - \\
\hline Pseudorhabdion cf. longiceps & - & $\mathrm{X}$ & - & - \\
\hline \multicolumn{5}{|l|}{ Pareatidae } \\
\hline Aplopeltura boa (Boie, 1828) & - & $x$ & - & - \\
\hline Pareas margaritophorus (Jan, 1866) & - & - & $\mathrm{X}$ & - \\
\hline Pareas sumatranus (Raffles, 1822) & $X$ & - & - & - \\
\hline \multicolumn{5}{|l|}{ Homalopsidae } \\
\hline Hypsiscopus plumbea (Boie, 1827) & - & - & $\mathrm{x}$ & - \\
\hline \multicolumn{5}{|l|}{ Natricidae } \\
\hline Macropisthodon rhodomelas (Boie, 1827) & - & - & - & $x$ \\
\hline Rhabdophis chrysargos (Schlegel, 1837) & $\mathrm{X}$ & - & - & - \\
\hline \multicolumn{5}{|l|}{ Elapidae } \\
\hline Calliophis bivirgata (Boie, 1827) & - & - & $\mathrm{X}$ & - \\
\hline \multicolumn{5}{|l|}{ Viperidae } \\
\hline Parias hageni (Lidthe de Juede, 1886) & - & - & - & $X$ \\
\hline Popeia fucata (Vogel, David \& Pauwels, 2004) & $\mathrm{X}$ & $\mathrm{X}$ & - & - \\
\hline Tropidolaemus wagleri (Wagler, 1830) & - & - & - & $X$ \\
\hline \multicolumn{5}{|l|}{ TURTLES } \\
\hline \multicolumn{5}{|l|}{ Geomydidae } \\
\hline Heosemys spinosa (Gray, 1830) & $\mathrm{X}$ & - & $\mathrm{X}$ & - \\
\hline \multicolumn{5}{|l|}{ Trionychidae } \\
\hline
\end{tabular}






Figures 7-9. Gunung Tebu habitat. 7: Punca Air at 550 m, 8: Hill dipterocarp forest at 700 m, 9: Summit of Gunung Tebu.

LSUHC refers to La Sierra University Herpetological Collection; LSUDPC refers to La Sierra University Digital Photographic Collection; USMHC refers to Universiti Sains Malaysia Herpetological Collection. For taxonomies of the lizards we follow Grismer (2011a,b), amphibian taxonomy follows Frost (1985), and snake taxonomy follows Tweedie (1983).

Fifty species of frogs from 20 genera and six families; 35 species of lizards from 19 genera and four families; 18 species of snakes from 12 genera and six families; and three species of turtle from three genera and three families were recorded from Gunung Tebu, Gunung Lawit, and the surrounding lowlands (Table 1).

\section{Amphibians \\ Family Bufonidae}

Ansonia latifii Wood, Grismer, Norhayati \& Senawi, 2008 (Figure 10)

Lata Tembaka: LSUHC 9801: Lata Tembaka, 3 July 2010. LSUHC 99035 September 2010. Base of Gunung Lawit LSUHC 8315-16, 23 June 2012.

An adult female (LSUHC 9801, SVL $53 \mathrm{~mm}$ ), a subadult female (LSUHC 9903, SVL $34 \mathrm{~mm}$ ), and two specimens (LSUHC 8315, SVL $34 \mathrm{~mm} ; 8316$, SVL $38 \mathrm{~mm}$ ) agree in morphology with Wood et al.'s (2008) diagnosis of Malaysian specimens collected from Hutan Lipur Sekayu, Terengganu (LSUHC 10325), and Gunung Lawit (LSUHC 8315-16) in having the snout projecting beyond lower jaw; a small, whitish-yellow wart at the angel of the jaw; no tuberculate interorbital ridges; a narrow head and snout (females); rounded finger tips; first finger reaching the same level as the tip of the second; inner and outer metatarsal tubercles present; single (LSUHC 9903) or double (LSUHC 9801) mandibular asperities formed by low, ridged tubercles lacking keratinized, spinose tips; upper jaw having similar asperities; dorsolateral row of tubercles absent; faint, white spot between scapulae; keratinized, spineless tubercles in gular region in females extending onto chest; abdomen finely granular; iris reddish gold with dark lines in life; and gular spotting present. We suspect that the A. malayana Dring collected from Gunung Tebu was actually $A$. latiffi based on his description.

LSUHC 9801 was collected at night from within a mossy hole near sewage along a riverbank and LSUHC 9903 was found on a leaf in an open area along a small stream. LSUHC 8315-16 were found on leaves along a rocky stream. Dring (1979) listed this species as Ansonia sp. and collected this species from Sungai Keleband at $43 \mathrm{~m}$. 


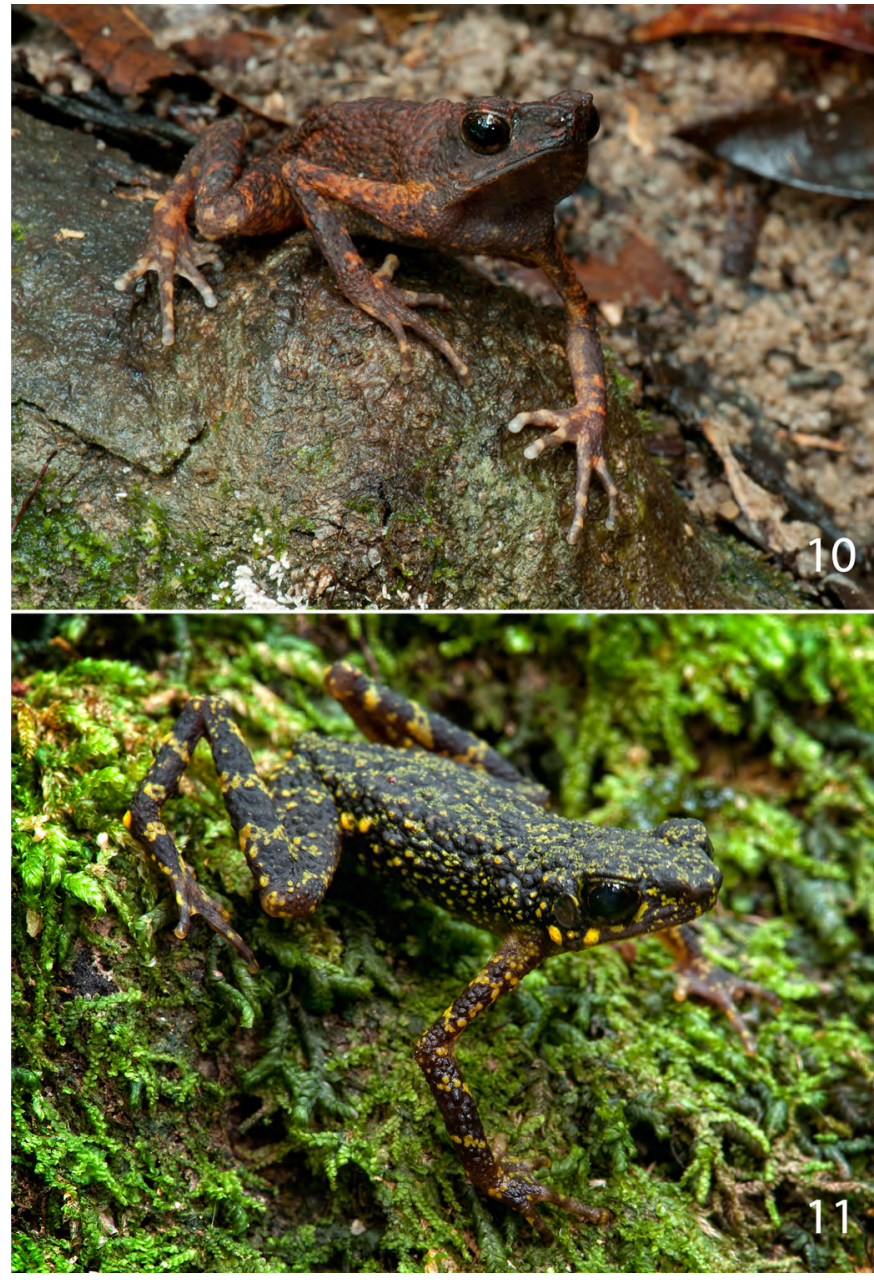

Figures 10 and 11. Recently described Ansonia species. 10: Ansonia latifii from Hutan Lipur Lata Tembaka. 11: Ansonia lumut from Punca Air, Gunung Tebu.

Ansonia lumut Chan, Wood, Anuar, Muin, Quah, Sumarli \& Grismer, 2014 (Figure 11)

580-800 m on Gunung Tebu: LSUHC 10898-900, 2 September 2012.

All specimens agree in morphology with Chan et al. (2014) in having a small body size (SVL 21-23.6 mm); slender limbs; no parotoid glands; weak subarticular tubercles; and membranous foot webbing; first finger shorted than second; absence of interorbital and tarsal ridges; distinct dorsal tubercles and dorsolateral row of enlarged tubercles; finger tips not expanded into discs; slightly less than two phalanges free of web on fifth toe; light interscaular spot and light patch below eye absent; presence of large, yellow rectal tubercle; dorsum black with greenish-yellow reticulations; flanks with small yellow spots; fore and hind limbs with yellow crossbars; venter light gray with fine, white spotting; and males with nuptial pads on first finger.

All specimens were collected at night from moist rocks near a stream; small, fern-like leaves; and mossy granite crevices. Dring (1979) listed this species as A. malayana and collected two individuals from within a rock crack and in leaf letter at 1,000 m on Gunung Lawit.
Duttaphrynus melanostictus (Schneider, 1799)

Lata Belatan: USMHC 1040, 9 July 2012.

A single adult female (USMHC 1040, SVL 55mm) agree with Grismer's (2011a) diagnosis of Malaysian specimens from Pulau Tioman in having a stout body, relatively small head, snout obtuse; black bony crest border posterior portion of eyes and extend to parotid glands; parotid glands elongate and stippled with black; tympanum distinct; limbs short and robust; digits short and blunt, toes more than $1 / 2$ webbed. The dorsum was yellowish and the skin is rough and warty.

The specimen was collected along the road at night around the Lata Belatan car park area. The behavior fits that mentioned by Grismer (2011a) that comments that this species is a common inhabitant of disturbed areas.

\section{Ingerophyrnus parvus (Boulenger, 1887)}

Lata Belatan: LSUHC 10830, 31 August 2012. USMHC 1087, 12 July 2012 Lata Tembaka: LSUHC 9795-96, 9800, 2 July 2010. LSUHC 9885-86, 9894, 9907, between 6 September 2010 and July 2010. Base of Gunung Lawit: LSUHC 8269, 8289, 8301, 22 June 2012.

Two adult males (LSUHC 9796 and 10830, SVL 33 $\mathrm{mm}$ ), one subadult female (LSUHC 9795 SVL $36 \mathrm{~mm}$ ), and three specimens from Gunung Lawit (LSUHC $8269,8289,8301$ ) mostly agree with Grismer's (2011a) diagnosis of Malaysian specimens from Pulau Tioman (LSUHC 3882, 3967, 3969-71, 3976-77, 3981) by exhibiting a stout medium-sized body; head as wide as the body; snout rounded; two boney, parallel crests between eyes and one short crest above tympanum; oval to round parotid glands; moderately sized eyes; distinct tympanum up to $3 / 4$ diameter of the eye; short limbs, not overly robust; rounded digits with toes $1 / 2$ webbed; no tarsal fold; rough warty skin; dorsal pattern consists of paired, dark, paravertebral markings; thigh and foreleg have a single dark band that becomes contiguous when the knee is flexed; and chest and belly light-colored and lightly spotted. They disagree by lacking black-tipped warts throughout the dorsum and having a dark instead of a light dorsum. One tadpole, LSUHC 9800, matches Grismer's (2011a) description in having a round to oval head-body; dorsal and caudal fins deeper than tail musculature; and caudal fins slightly lighter in color. LSUHC 9800 had a light colored head-body and tail musculature, and small black dots scattered randomly throughout the entire body.

Individuals of this species were commonly observed at night calling from rocks and swampy areas along streams and small riverbanks. They were also active on the forest floor and on the leaves of low vegetation. LSUHC 9800 was found swimming in a puddle at the water's edge. Specimens collected by Dring (1979) from Gunung Lawit and Grismer (2011a) showed similar behavior. 
Phrynoides aspera (Gravenhorst, 1829)

Lata Tembaka: LSUHC 9902, September 2012. Base of Gunung Lawit: LSUHC 8264, 8265, 22 June 2012. Lata Belatan: USMHC 1048, 9 July 2012.

An single adult from Lata Tembaka (LSUHC 9902, SVL $36 \mathrm{~mm}$ ), adult male from Lata Belatan (USMHC 1048, SVL 105mm) and two specimens from Gunung Lawit match Berry's (1975) description of this species from Peninsular Malaysia and Grismer's (2011a) description of specimens from Pulau Tioman (LSUHC $4447-48,4572,4643,6315)$ in having a relatively flat, dorsoventrally compressed body; head wider than long with an obtuse snout; cranial crests absent; oval to round parotid glands same size as eyes; eyes moderately sized; distinct tympanum $1 / 3$ the size of the eye; stout limbs; tips of digits bulbous; all toes except the fourth completely webbed; tarsal fold present; rough and warty skin; dark-brown dorsum; iris silver; and chest and belly light-colored.

The specimen from Lata Tembaka was collected at night sitting on the forest floor approximately $100 \mathrm{~m}$ from the river and was easily approached. The male from Lata Belatan was collected at night sitting on a boulder in the river. The two speciems from Gunung Lawit were found along a stream near base camp. Dring (1979) noted that adult and subadult individuals from Gunung Lawit were confined to rivers while juveniles were found along logging tracks and small streams.

\section{Family Dicroglossidae}

\section{Fejervarya limnocharis (Boie, 1835)}

Lata Belatan: USMHC 1038, 1039, 9 July 2012.

The subadult male (USMHC 1038 , SVL $35 \mathrm{~mm}$ ) and the adult female (USMHC 1039, SVL 57mm) match Berry's (1975) diagnosis in having vomerine teeth in two oblique series between the choanae; head moderate; pointed snout; tympanum approximately $3 / 5$ of eye diameter; finger and toes pointed; first finger longer than second; fingers lacking fringes of skin; toe webbing deeply excised, leaving at least one phalanx of each toe free; fifth toe with $1 \frac{1 / 3}{3}$, and fourth toe with three phalanges free; a low ridge of skin on outer edge of the fifth toe; an elliptical, inner metatarsal tubercle; and a small, outer metatarsal tubercle.

The specimens were collected at night from leaf litter near a swampy area in secondary forest.

\section{Limnonectes blythii (Blyth, 1856)}

580-80o meters on Gunung Tebu: LSUHC 10897, 2 September 2012. LSUHC 11173, 30 June 2013. Lata Tembaka: LSUHC 9897, September 2010. Base of Gunung Lawit: LSUHC 8270-72, 22 June 2012.

A subadult female (LSUHC 10897, SVL $72 \mathrm{~mm}$ ), an adult male (LSUHC 11173, SVL $123 \mathrm{~mm}$ ), an adult female
(LSUHC 9897, SVL $75 \mathrm{~mm}$ ), and three specimens from Gunung Lawit mostly agree with Grismer's (2011a) description of specimens from Pulau Tioman (LSUHC $5484-86,5497-98,5500,5505,5513$ ) by having a stout body with a broad head rounding into a pointed snout; eyes moderate in size; tympanum distinct $1 / 4-2 / 3$ the size of the eye; tips of digits slightly swollen; toes $3 / 4$ webbed; scattered low tubercles along smooth skin; brown to black bands on the lip; and a supratympanic fold. LSUHC 9897 and 10897 have a distinct, light-yellow, vertebral stripe not usually observed in streamside dwelling frogs of this species. The vertebral stripe fades on the head in LSUHC 10897. The Lata Tembaka specimen, LSUHC 9897, lacked the light-yellow, vertebral stripe typically observed in forest floor dwelling Limnonectes blythii.

The individuals were collected at night sitting on rocks and within shallow pools alongside a clear flowing stream surrounded by primary forest. This species was fairly common in streamside habitats and males could be heard calling at night at Gunung Tebu. At Lata Tembaka, LSUHC 9897 was collected at night on the forest floor approximately $50 \mathrm{~m}$ away from the stream. Dring (1979) reported similar observations and noted that this was most common river frog at Gunung Lawit. All specimens from Gunung Lawit were collected along streams.

\section{Limnonectes kuhlii (Duméril \& Bibron, 1841)}

580-80o meters on Gunung Tebu: LSUHC 10890-96, 2 September 2012. LSUHC 11164-67, 30 June-2 July 2013; USMHC 1077, 10 July 2012.

A series of twelve adult specimens (LSUHC 10890-96, 11164-67, USMHC 1077 SVL 78-110 mm) mostly concur with Berry's (1975) diagnostic characters of this species from Peninsular Malaysia in having vomerine teeth; disk on the fingers not significantly larger than the tympanum; toe tips pointed and lacking a circum-marginal horizontal groove; tips of toes expanded into small disks that are wider than the penultimate phalanges; the tympanum not visible through the skin; and all toes broadly webbed to disks with a freely movable flap of skin of the outer edge of the fifth metatarsal. LSUHC 10896 (SVL $110 \mathrm{~mm}$ ) and LSUHC 11106 (SVL $108 \mathrm{~mm}$ ) exceed Berry's total length of approximately $90 \mathrm{~mm}$.

All individuals were collected from habitats similar to Dring's (1979) specimen from Gunung Lawit. They were found at night on moist granite rocks along a cool and clear flowing stream shaded by primary forest and mossy vegetation growing along the bankside. Although frogs where observed during the day in the water at the base of large granite rocks, they were only active at night.

\section{Limnonectes laticeps (Boulenger, 1882)}

Lata Tembaka: LSUHC 9906, 5 and 6 September 2011. LSUHC 10856-57, 10874-75: 2 September 2012. 800 meters on Gunung Tebu: LSUHC 11163, 11169, 11174, 30 
June 2013, USMHC 1074, 10 July 2012. Base of Gunung Lawit: LSUHC 8273-75, 8311, 22 June 2012. Lata Belatan: USMHC 1067, 11 July 2012.

Four adult females (LSUHC 9906, 10856, 11169, 11174, SVL 38-49 mm), one adult male (LSUHC 10857, SVL 35 $\mathrm{mm}$ ), five juveniles (LSUHC 10874-75, 11163, USMHC 1067, 1074 SVL 17-27 mm), and three specimens from Gunung Lawit agree with Berry's (1975) diagnostic characters of this species in having vomerine teeth present; finger disks much smaller than tympanum; pointed toe tips lacking circum-marginal horizontal grooves; tips of toes expanded into small disks wider than penultimate phalanges; tympanum not discernable from skin; toes not fully webbed to disk; no freely moving flap of skin on outer edge of fifth toe; and skin of lower leg smooth lacking distinct, rough tubercles.

All specimens were found at night on smooth, damp rocks and shallow pools near streams and seepages where males where heard calling. A termite was found in the mouth of LSUHC 11174 indicating that it had been hunting prior to capture. Dring (1979) noted that this species and Amalops larutensis, were the only frogs collected between $43^{-1,280} \mathrm{~m}$ on Gunung Lawit. This was similarly observed on Gunung Tebu where they were found at the base of the mountain at Lata Belatan up to the montane areas slightly above $800 \mathrm{~m}$.

\section{Limnonectes plicatellus (Stoliczka, 1873)}

Base of Gunung Lawit: LSUHC 8312, 23 June 2012.

A juvenile female (SVL $22.5 \mathrm{~mm}$ ) agrees with Berry's (1975) description in having vomerine teeth in two oblique series, commencing on a line with the hinder edge of the choanae; lower jaw with two fang-like projections in front; head large; snout bluntly pointed; tympanum distinct; finger tips dilated into small but distinct disk without circum'marginal grooves; first finger tip slightly larger than second; toe tips like those of fingers; $2 / 3$ to $3 / 4$ webbed; subarticular tubercles well developed; inner metatarsal tubercle elongate; no outer metatarsal tubercle; a very slight tarsal fold; skin of back with many (8 to 10 distinct, discontinuous longitudinal folds; upper eyelid tubercular; and a strong supratympanic fold. The individual also had a yellow vertebral stripe that Berry noted may or may not be present in this species. Additionally, Berry reported that males of this species have a medium, knob-like bony prominence on the dorsal surface on the head between the eyes.

The specimen was collected from the ground on a trail near the Gunung Lawit base camp.

\section{Occidozyga martensii (Peters, 1867)}

Lata Tembaka: LSUHC 8320, 24 June 2012. Lata Belatan: LSUHC 10832-10833, 31 August 2012. USMHC 1053, 10 July 2012. Base of Gunung Lawit: LSUHC
8282-8285, 8292, 93, 22 June 2012.

All individuals agree with Parker's (1934) description and specimens from West Malaysia (LSUHC 6881-84, 7197) in lacking vomerine teeth; having a rounded posterior tongue margin; small terminal disk at tips of digits; no longitudinal dorsal grooves; and relatively small body size, SVL 22-28 $\mathrm{mm}$.

Specimens from Lata Belatan were collected from a swampy area on the forest floor in disturbed areas. Individuals from Lata Tembaka were found along a stream. Specimens from the base of Gunung Lawit were collected along a stream and puddles near camp.

\section{Taylorana hascheanus (Stolickza, 1870) (Figure 12)}

600-750 $\mathrm{m}$ on Gunung Tebu: LSUHC 10840-43, 1 September 2012.

Three adult females (LSUHC 10840-43, SVl 31-38 $\mathrm{mm}$ ) and one adult male (LSUHC 10841, SVL 24 $\mathrm{mm}$ ) agree somewhat with Berry's (1975) diagnostic characters of this species in having vomerine teeth; finger disks smaller than tympanum; blunt, pointed toe tips lacking horizontal circum-marginal grooves; toe tips expanded into small disks wider than penultimate phalanges; tympanum visible and approximately $2 / 3$ size of eye; on some specimens, a dark, temporal spot not covering entire tympanum is present; webbing not reaching the disks of the second and third toes on the inner sides; having a small body size less than $60-75 \mathrm{~mm}$ SVL; three phalanges of the fourth toe free of web; no distinct dorsolateral fold; nostrils facing more laterally than dorsally. The specimens herein differ from Berry (1975) by the anterior margins of vomerine patches being on a line with the middle or anterior edges of choanae. LSUHC 10843 has a thin, white vertebral stripe extending from just anterior the eyes to the vent.

All specimens were collected at night on the ground below the front porch of a chalet.

\section{Family Microhylidae}

Kalophrynus pleurostigma (Tschudi, 1838) (Figure 13) Lata Tembaka: LSUHC 8828, 12 March 2008.

The single specimen (SVL $22 \mathrm{~mm}$ ) matches Berry's (1975) diagnosis in having a prominent snout; head wider than long; distinct tympanum nearly as large as eye diameter; finger tips rounded, not expanded; first and fourth shorter than second; subarticular tubercles prominent; toe tips like those of fingers; first three toes and fifth toe each with one phalanx free of web; fourth toe with $3-3^{1 / 2}$ phalanges free; an oval, inner, metatarsal tubercle; a round outer metatarsal tubercle; skin granular above and below, coarsely granular on belly; and a curved supratympanic fold.

The individual was collected during the day from the 


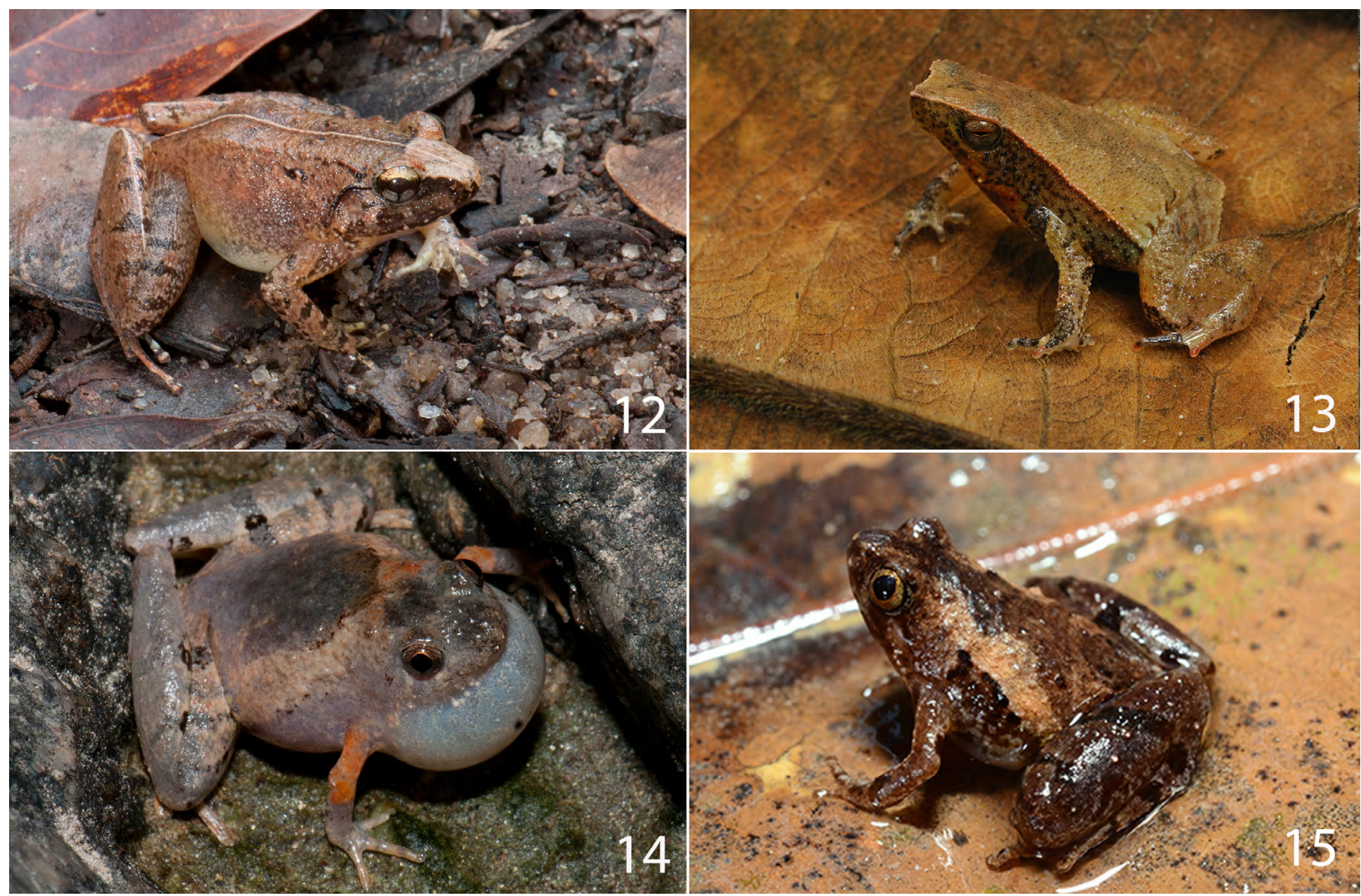

Figures 12-15. Lowland frogs. 12: Taylorana hascheanus from Lata Tembaka. 13: Kalophrynus pleurostigma from Lata Tembaka. 14: Microhyla cf. berdmorei from Lata Tembaka, 15: Microhyla supercilaris from Lata Belatan.

base of a large dipterocarp, tree on the side of a hill deep within primary rainforest. Dring collected this specimen in leaf litter in secondary forest at Sungai Kelebang.

\section{Microhyla berdmorei (Blyth, 1856) (Figure 14)}

Lata Tembaka: LSUHC 9797-98, 2 July 2010.

Two subadult males (LSUHC 9797, SVL 23; LSUHC 9798, SVL $25 \mathrm{~mm}$ ) agree with Berry's (1975) diagnosis of specimens from Peninsular Malaysia in having no dermal projection at the heel and elbow; fingers lacking greatly enlarged, flat tubercles and no double sets at their bases; no teeth on jaws; low, rounded, inner metatarsal tubercle; tympanum hidden by skin; both inner and outer metatarsal tubercles present; webbing reaching disks of first and fifth toe; toe disks with a median distal notch on upper portion; and toes almost completely webbed, with low point of web between third and fourth toes at the level of the terminal and penultimate subarticular tubercles of fourth toe.

Both males were collected at night while calling from within puddles on the top of a boulder at the water's edge. Dring's (1979) specimens from Sungai Kelebang were collected from disturbed areas and were often within the vicinity of Microhyla heymonsi and Microhyla borneensis.
Microhyla fissipes Matsui et al., 2005

Lata Belatan: USMHC 1031, 9 July 2012; USMHC 1052, 10 July 2012

The two adult specimens (USMHC 1031, SVL 21mm; USMHC 1052, SVL 26mm) match Berry's (1975) diagnosis of Microhyla ornata specimens from Peninsular Malaysia that $M$. fissipes were once synonymized with by Parker (1928) but subsequently removed from synonymy by Matsui et al. (2005). Snout is obtusely pointed; tympanum hidden; finger tips slightly swollen; first much shorter than second; tips of toes similar to fingers; toes with slight rudimentary webbing; subarticular tubercles very distinct; two small but prominent, subequal metatarsal tubercles. Skin is smooth and color is greyish olive above with a large dark marking on the back, beginning between the eyes and widening as it extends to the posterior of the body with wavy dusky lines along each side of this marking. A dark band is present along the sides of the head and body and the limbs have dark cross-bars. The throat was grayish with faint white spots while the belly is immaculate gray.

The specimens were collected on the ground at night beside some puddles in a cleared area close to the carpark. Other species found within the vicinity were Microhyla heymonsi, Occidozyga martensi, Polypedates leucomystax and Enhydris plumbea. 
Microhyla heymonsi (Vogt, 1911)

Lata Belatan: LSUHC 10961 (USMHC 1032), USMHC 1031, 9 July 2012.

Both specimen agrees with Parker's (1934) diagnosis of material from Taiwan, Southern China, Hainan, Tonkin, Thailand, Cochin China, Peninsular Malaysia, Nias, and Sumatra, and specimens from throughout northern Malaysia (LSUHC 6511-12, 6654, 6658) in having a snout no longer than twice the diameter of the eye; toes not more than $1 / 3$ webbed with small disks with a medial groove; outer metatarsal tubercle divided; and a continuous dark stripe from snout to groin. LSUHC 10961 has a thin, light-colored vertebral stripe running from snout to vent.

The individuals were caught on the ground near puddles in grassy areas where several other males could be heard calling. Dring (1979) observed similar behavior from specimens collected from disturbed areas at Sungai Kelebang.

Microhyla supercilaris (Parker, 1928) (Figure 15)

Lata Belatan: USMHC 1050, 1051, 9 July 2012.

Both specimens (SVL $13 \mathrm{~mm}$ ) match Berry's (1975) description in having a round snout; tympanum hidden; finger tips scarcely dilated; first finger much shorter than second; toe tips dilated with circum-marginal grooves; no notch on upper half of disks; toes almost fully webbed; broad webbing extending to disks of all except the fourth toe; subarticular tubercles scarcely distinct; smooth skin throughout body; a dermal spine above upper eyelid; and two metatarsal tubercles.

Both individuals were found in a leaf filled puddle along the main river.

Metaphrynella pollicaris (Boulenger, 1890) (Figure 16) 600-750 meters on Gunung Tebu: LSUHC 10846, 1 September 2012. Over 800 meters on Gunung Tebu: LSUHC 10876, 2 September 2012: LSUHC 10965 (USMHC 1071), 10 July 2012. Between camp and peak on Gunung Tebu: LSUHC 11228, 2 July 2013.

Five adult males (SVL 28-29 mm) match Berry's (1975) description in having short and small heads; truncate, projecting snouts; tympanae hidden; fingers depressed with tips expanded into large sub-triangular disks; subarticular tubercles flat and very prominent; a double set of tubercles at bases of third and fourth fingers; in males polex extends beyond distal edges of subarticular tubercles of first fingers; fingers webbed at base; toe tips resembling fingers; toes approximately half webbed not reaching beyond distal subarticular tubercles of the second, third and fifth toes.

This species was heard calling at night in thick primary

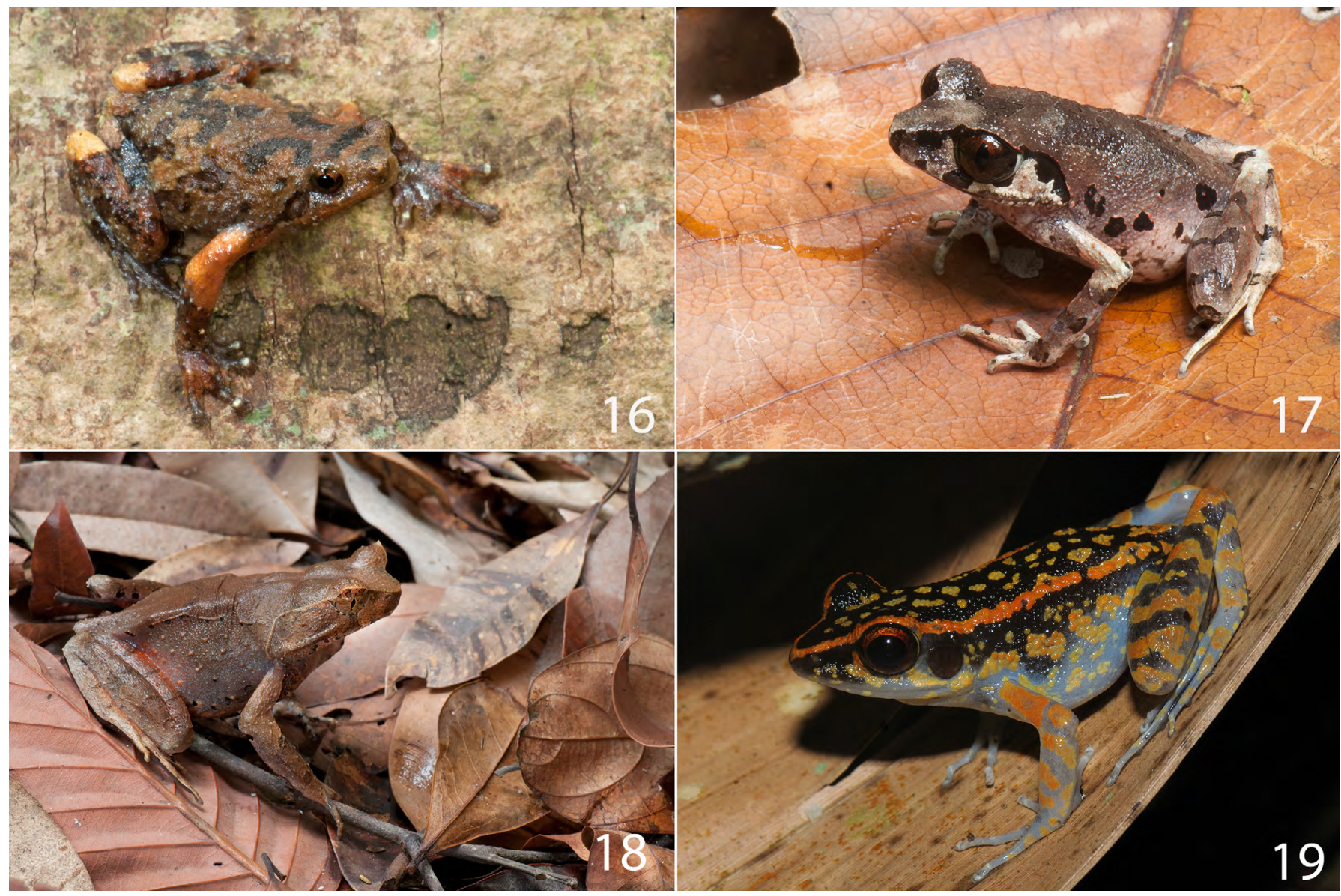

Figures 16-19. Frogs from Gunung Tebu and Lata Tembaka. 16: Metaphrynella pollicaris from Gunung Tebu, 17: Leptolalax sp. from Gunung Tebu, 18: Xenophrys aceras from Gunung Tebu, 19: Hylarana picturata from Lata Tembaka. 
forest within the knotholes of thin trees approximately 3-4 $\mathrm{m}$ above the ground. Calling activity increased during the rain. Dring (1979) found this species between 780-1,520 m (the summit) of Gunung Lawit. Knotholes from where they were calling ranged from $0.5-6 \mathrm{~m}$ above the ground. Most calling was from the eastern side of Gunung Lawit and occurred at night whereas individuals from over $1290 \mathrm{~m}$ started calling in late morning.

\section{Family Megophryidae}

Leptobrachium hendricksoni (Taylor, 1962)

Lata Tembaka: LSUHC 8338, 24 June 2012. Lata Belatan: LSUHC 10829, 31 August 2013. USMHC 1065, 11 July 2012. Base of Gunung Lawit: LSUHC 8276, 8309, 8310, 8313, 22 June 2012.

Two adult males (LSUHC 8338, 10829), one adult female (USMHC 1065), and four specimens (LSUHC 8276, 8309, 8310, 8313) from Gunung Lawit closely match Taylor's (1962) description of specimens collected from Thailand and Berry's (1975) diagnosis of Peninsular Malaysian specimens in having a broad head; no vomerine teeth; tongue notched behind; tympanum distinct about $1 / 2$ the dye diameter; finger tips rounded, not swollen; first and second fingers subequal, fourth shorter, third much longer; subarticular tubercles irregular in disposition; two round and large metacarpal tubercles, the inner a little larger than the outer; tips of toes like those of fingers; webbed at base to half webbed; inner metatarsal tubercle low, oval; no outer metatarsal tubercle; tibiotarsal joint reaches to shoulder or tympanum; skin above smooth; and supratympanic fold from eye to axilla.

LSUHC 8338 was collected from along a river while LSUHC 10829 and USMHC 1065 were collected on the forest floor in a swampy area. All specimens from the base of Gunung Lawit were collected along a stream and the trail. Dring (1979) recorded this specimen as Leptobrachium hasselti, which is not recognized from Peninsular Malaysia and was most likely a misidentification of L. hendricksoni (Chan et al. 2009b).

\section{Leptolalax sp. nov. (Figure 17)}

600-750 meters on Gunung Tebu: LSUHC 10844-45, 1 September 2012. Over 640 meters on Gunung Tebu: LSUHC 10855, 10885; 2 September 2012: LSUHC 1096667, 10 July 2013.

Character data on these specimens indicate that although this specie resembles Leptolalx heteropus it is a new species and is currently being described. Individuals were collected from leaf litter on the forest floor, on the front porch of a chalet, and along a dirt trail. Dring (1979) collected specimens of this species from steams on Gunung Lawit, but listed them as Leptobrachium heterpous.

\section{Megophrys nasuta (Schlegel, 1858)}

Base of Gunung Lawit: LSUHC 8303, 8314, 23 June 2012

A sub adult specimen and a juvenile specimen agree with Berry's (1975) description in having vomerine teeth present; dermal projection on edge of upper eyelid; tongue notched behind; tibiotarsal joint reaching about to the level of the forelimb when adpressed against the body; a prominent, well-developed dermal projection off tip of snout; and two pairs of dorsolateral longitudinal skin folds.

Both individuals were caught from a stream near the Gunung Lawit base camp. Dring (1979) collected tadpoles of this species in a fast flowing tributary near the shore of Sundai Kelebang. He also found immature frogs 250-300 $\mathrm{m}$ on the lower slopes of Gunung Lawit and head males along the river.

\section{Xenophrys aceras (Boulenger, 1903) (Figure 18)}

600-750 meters on Gunung Tebu: LSUHC 10847,10848, 1 September 2012. USMHC 1076, 10 July 2012.

Two adult females (LSUHC 10847-48) and one adult male (USMHC 1076) match Taylor's (1962) description of specimens collected from Thailand, and Berry's (1975) more recent diagnosis in having a large head, 1.25-1.75 times as broad as long; tongue notched posteriorly; vomerine teeth present; snout truncate, projecting beyond lower jaw; a small soft dermal projection on the edge of the upper eyelid; sharp canthus rostralis; tympanum feebly distinct; first finger a little longer than the second; no subarticular tubercles and distinct metacarpal tubercles; toes short and feebly swollen at tips with rudiment of a web; flat, but distinct inner metatarsal tubercle; tibio-tarsal joint reaching to approximately the forelimb; no dermal projection off snout tip; a single pair of longitudinal skin folds on back; skin smooth; a distinct supratympanic fold extending from eye to shoulder; and ventral surface with small tubercles.

All specimens were collected on a trail at night in hill dipterocarp forest. Dring (1979) also collected specimens from similar habitats and from streams on Gunung Lawit.

\section{Family Ranidae}

\section{Amolops larutensis (Boulenger, 1899)}

Lata Tembaka: LSUHC 9787-92, 2 July 2010. Lata Belatan: LSUHC 10950-59, 9-11 July 2012. Gunung Lawit: LSUHC 8278-81, 8305-08. Gunung Tebu: LSUHC 10889, 10950, 2 September 2012.

Five specimens (LSUHC 9787-92, 10951-59, 10889, 10950; SVL 31-79 mm) and eight specimen from Gunung Lawit (LSUHC 8278-81, 8305-08) agree with Berry's (1975) diagnosis of Peninsular Malaysian specimen by 
having vomerine teeth; toe and finger tips expanded into distinct disks bearing circum-marginal grooves; disk of the longest finger distinctly larger than the tympanum; sub-articular tubercles indistinct; a small, but distinct outer metatarsal tubercle; and skin finely granular with some flat, enlarged tubercles on sides of body. LSUHC 9791and 10950 are not described.

All individuals were collected at night from the top of damp rocks within a fast flowing stream. Dring (1979) collected specimens between 43-1,280 m on Gunung Lawit from similar habitats.

\section{Hylarana labialis (Boulenger, 1887)}

Lata Belatan: LSUHC 10972, USMHC 1021, 9 July 2012. Base of Gunung Lawit: LSUHC 8266-88, 8302, 22 June 2012.

Specimens agree with Berry's (1975) diagnosis of Peninsular Malaysian Specimen and Grismer's (2011a) description of Malaysian specimens collected from Pulau Tioman $(3768,3803,3805,3884-86,3909-10$, 3913, 4630-34, 4641, 4645, 4648, 5423, 5466, 5468-70, $5490,5492-94,5503)$ in having an elongate, narrow body with a tapered head and pointed snout; eyes large; tympanum distinct, $2 / 3$ to $3 / 4$ diameter of eye; limbs long and muscular; tips of digits expanded to form round disks each with a circum-marginal groove; toes fully webbed except for fourth toe; oval, inner, metatarsal tubercle and round, outer metatarsal tubercle present; skin finely pebbled with a texture of ground glass; weak, dorsolateral fold on body; supratympanic fold absent; and upper lip white.

This species was collected at night while sitting along a stream next to a dirt trail. Grismer (2011a) reported similar observations. Specimens from Gunung Lawit were collected along stream.

\section{Hylarana laterimaculata (Barbour \& Noble, 1916)}

Lata Belatan: USMHC 1075, 11 July 2012.

The adult male (SVL 40mm) match Leong et al.'s (2003a) description of Rana laterimaculata specimens from Peninsular Malaysia in having humeral glands (only in males); nuptial pads; paired subgular vocal sacs to $39.0 \mathrm{~mm}$; dorsolateral skin folds; scattered tubercles over dorsum and flanks; finger and toe tips slightly expanded into discs not wider than twice the width of penultimate phalanx; webbing of fourth toe not reaching middle sub-articular tubercle on both sides; tympanum entirely blac; and an uninterrupted white line on upper lift from posterior margin of tympanum to below eye.

The species was also collected by Dring (1979) at Gunung Lawit but at that time recognized at Hylarana baramica where it has been synonymized by Inger (1966) and subsequently resurrected by Leong et al. (2003b).

The specimen from Lata Belatan was collected at night from the undergrowth in a swampy area along a stream. Other males were heard calling in the vicinity.

\section{Hylarana glandulosa (Boulenger, 1882)}

Lata Belatan: USMHC 1018, 1041, 9 July 2012.

Two adults (USMHC 1018, SVL 83mm) \& (USMHC 1041, SVL 95mm) match Berry's (1975) diagnosis of the species; vomerine teeth in two short oblique series between choanae; head large; snout rounded, not projecting in profile; tympanum conspicuous, about $2 / 3$ to $3 / 4$ eye diameter. Finger tips dilated into small disks bearing interrupted circum-marginal grooves; first finger much longer than second; fingers without fringes or flaps; a supernumerary tubercle on all metacarpals. Tips of toes like those of fingers, but a little larger; first toe with two phalanges free of webbing, second with $1 \frac{1}{2}$, third with 2 , fourth with 3 to $3^{1 / 2}$, and firth with 1 to $1 \frac{1}{2}$; an oval inner and a smaller round outer metatarsal tubercle. Skin of dorsum with low rounded glandular warts; sides with larger and more prominent ones; no dorsolateral fold; a weak supratympanic fold from eye to axilla. Color was grayish brown above with small indistinct dark spots; sides spotted; lips dark, with large whitish spots or bars; limbs with dark cross-bars; lower parts whitish and spotted with brown.

Both specimens were collected along the river at night.

\section{Hylarana picturata (Boulenger, 1920) (Figure 19)}

Lata Tembaka: LSUHC 9791-92, 2 July 2011. Lata Tembaka: LSUHC 9884, 6 and 7 September 2011. Base of Gunung Lawit: LSUHC 8268, 8299, 8300, 22 June 2012.

Two sub adult females (9791-92, SVL $40 \mathrm{~mm}$ ), an adult male (LSUHC 9884, SVL $60 \mathrm{~mm}$ ), and three specimens from Gunung Lawit (LSUHC 8268, 8299, 8300,) match Berry's (1975) diagnosis of Peninsular Malaysian specimens and Grismer's (2011a) description of Malaysian specimens collected from Pulau Tioman (LSUHC 4435-41, 4436-40, 4665) in having a slender body, narrow head, and tapered snout; large eyes; tympanum distinct and $1 / 2$ the diameter of eye; limbs long and muscular; tips of digits form small, round disks each with a circum-marginal groove; toes slightly more than $1 / 2$ webbed; skin finely pebbled on back, but smooth on upper surface of leg; tympanic fold absent; body and sides black with yellowish to orange blotches; discontinuous yellow-orange, dorsolateral stripe extending from tip of snout through upper eyelid to groin; and ventral surfaces gray to brown, with small, yellowish spots.

All specimens were collected at night along the water's edge perched on rocks or deep within root systems. One specimen was found sitting on the sandy shore. Grismer (2011a) reported similar behavior. All specimens from the base of Gunung Lawit were collected along a rocky stream. Dring (1979) collected this species from Sunai Kelebang, but listed them as Rana signata signata a taxon restricted to Borneo. Populatons from Peninsular Malaysia are referred to as $H$. picturata. 
Odorrana hosii (Boulenger, 1891)

Lata Tembaka: LSUHC 9882-83, 6-7 September 2011. Lata Tembaka: LSUHC 9900, 5-6 September 2011. Lata Belatan: LSUHC 10970, USMHC 1036, 10379 July 2012.

Three adult females (LSUHC 9882-83, 9900; SVL 79-90 $\mathrm{mm}$ ) are in accord with Berry's (1975) diagnosis of Peninsular Malaysia specimen and Grismer's (2011a) diagnosis of Malaysian specimens collected from Pulau Tioman (LSUHC 3762-64, 3819, 3842-44, 3846, 4042, $4560,4565,4560-67,4577-78,4625-26)$ in having a moderately slender body with a long tapered head and pointed snout; large eyes; distinct tympanum $3 / 4$ the diameter of eye (in males); slender and muscular long limbs; fingers with narrow fringe of skin tips of digits expanded to form round disks each with a circum-marginal groove; toes fully webbed; oval, inner, metatarsal tubercle present; outer meter metatarsal tubercle absent; skin finely pebbled; weak dorsolateral fold on body; supratympanic fold absent; white upper lip; and grayish belly. This species exhibits vast color pattern variation in having the top of head and back green; sides and upper surfaces of legs usually brown; and various mixtures and green and brown throughout the body. The specimens fall within the color range of other Odoranna hosii collected in Peninsular Malaysia.

Frogs were collected at night from the riverbanks at Lata Tembaka and Lata Belatan. LSUHC 9900 was found near water in a drainage tube. Dring (1979) collected this species from Sungai Kelebang and Sungai Petuang.

\section{Family Rhacophoridae}

\section{Philautus petersi (Boulenger, 1900a)}

Over $800 \mathrm{~m}$ on Gunung Tebu: LSUHC 10854, 2 September 2012. LSUHC 11218-20, 30 June 2013.

Four adults (LSUHC 10854, 11218-20; SVL 25-28 $\mathrm{mm}$ ) agree with Grismer's (2011) diagnosis of Malaysian specimens collected from Pulau Tioman (LSUHC 4434, 4451, 5023-34) in having a robust body with a wide head and obtusely pointed snout with a small conical projection; large eyes; tympanum $2 / 3$ diameter of the eye and obscured by skin; long limbs; tips of digits expanded to form round disks each with a cirucum-margianl groove; toes $1 / 2$ webbed; fingers lack webbing; outer edge of $5^{\text {th }}$ toe weakly to moderately crenulated; skin smooth with irregularly distributed tubercles and short ridges; and variable shades of brown on the dorsum with an obscure dark X- or H-shaped marking.

This species was frequently heard at night calling from the surface of leaves and small twigs in thick primary forest. All the specimens were found on leaves approximately $2 \mathrm{~m}$ above the ground. Grismer (2011a) recorded similar observations. We suspect that the species that Dring (1979) listed as Philautus aurifasciatus is $P$. pertersi from Gunung Lawit.
Philautus vermiculatus (Boulenger, 1900a) (Figure 20) 600-750 meters on Gunung Tebu: LSUHC 10962-64, July 10 2012. LSUHC 10849, 1 September 2012. LSUHC 11221-22, 2 July 2013.

Five adult males (LSUHC 10962-64, 11221, SVL 28-35 $\mathrm{mm}$ ) and one adult female (LSUHC 11222, SVL $31 \mathrm{~mm}$ ) agree reasonably well with Berry's (1975) description of Peninsular Malaysian specimen in lacking vomerine teeth; fingers not conspicuously webbed; no prominent heel flap; outer two fingers free of webbing; webbing on feet does not reach disk of fifth toe; dorsal surface smooth or nearly so; tympanum not more than half eye diameter and obscured by skin; snout obtusely pointed in profile; ventral surface variably suffused with dark pigments; and throat spotted with brown. Not mentioned in Berry's (1975) diagnosis was the presence of bright yellow flash colors on the back and fronts of the thighs, the groin, and axillae of all specimens. Additionally, this series displays a vast array of color pattern variability. Philautus vermiculatus from Gunung Tebu differ from those from Bukit Larut by lacking pale-yellow to mahogany red transverse striations on the dorsal surface; and striations being wide to thin as opposed to thin and dispersed. Both display bright orange blotches throughout the throat, axilla, and caudal region.

This species could be heard at night calling from leaves, small branches, and low, mossy vegetation growing on or near the base of trees in dense primary forest both during dry and rainy periods. Dring (1979) reported similar observations and collected males calling from tree holes on Gunung Lawit. He hypothesized that the females of this species lay their eggs in tree holes and that males lead gravid females to these holes by calling.

\section{Polypedates leucomystax (Gravenhorst, 1829)}

Below 600 m on Gunung Tebu: LSUHC 10947, 10 July 2012. Lata Belatan: LSUHC 10975, USMHC 10199 July 2012 and 1 July 2013. Lata Tembaka: LSUHC 9901, 5-6 September 2012. Base of Gunung Lawit: LSUHC 8290, 91, 94-96, 22 June 2012.

Two adult males (LSUHC 9901, SVL $47 \mathrm{~mm}$; 10975, SVL $46 \mathrm{~mm}$ ), an adult female (LSUHC 10947, SVL $57 \mathrm{~mm}$ ), and 5 specimens from Gunung Lawit are in accord with Grismer's (2011a) diagnosis of Malaysian specimens collected from Pulau Tioman (LSUHC 3770, 3845,3871 ) in having a slender medium-sized body with a broad head and rounded, projecting snout; long, slender limbs; tips of digits expanded into round disks with circum-marginal grooves; fully webbed toes; fingers lacking webbing; smooth skin with a supratympanic fold; variable color pattern from light to dark tan with or without four dark, narrow vertebral stripes; dark longitudinal line usually present below supratympanic fold; ventral surfaces of thighs and sides of belly yellow; 


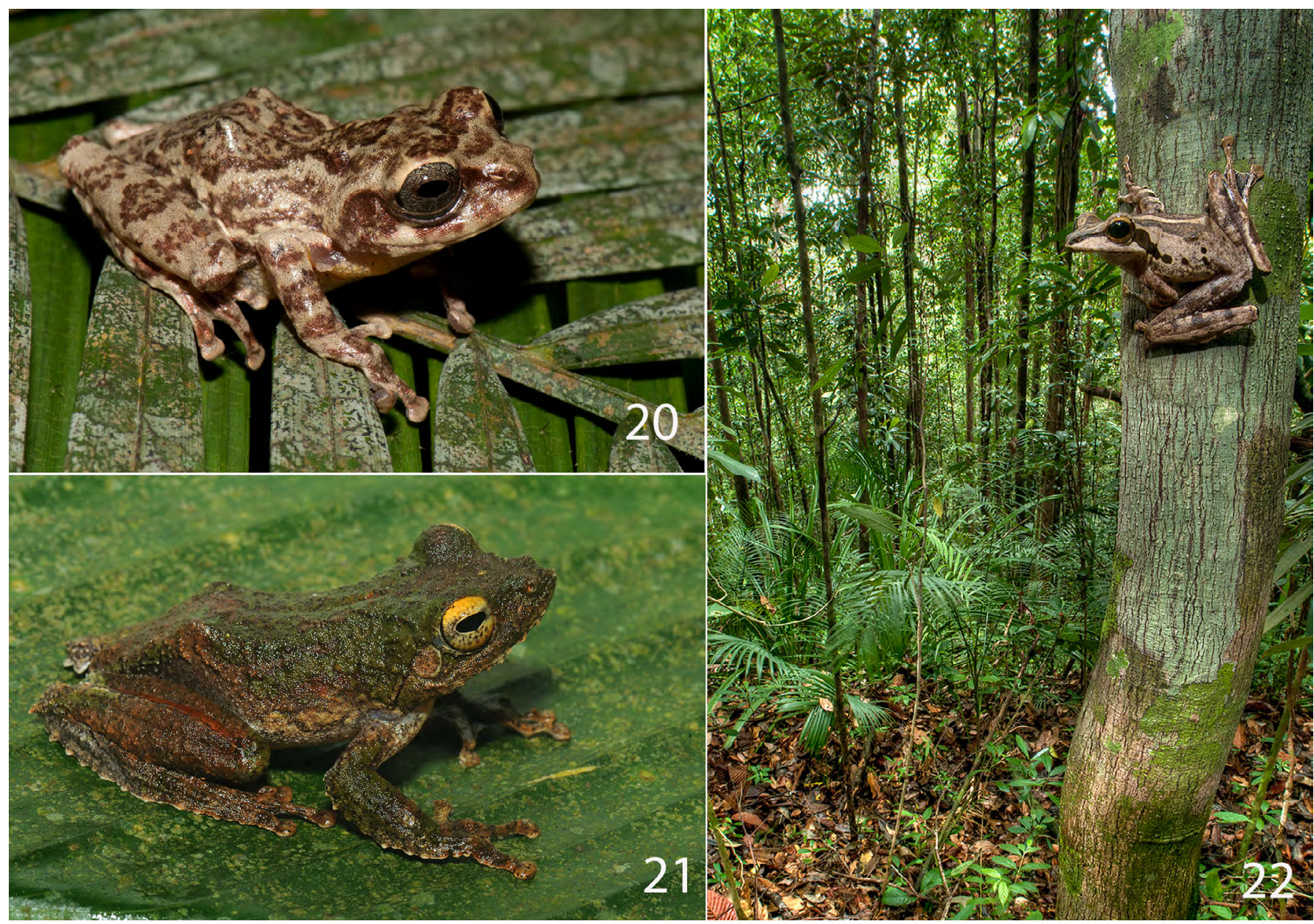

Figures 20-22. Frogs collected from Gunung Tebu and Lata Tembaka. 20: Philautus vermiculatus from Gunung Tebu. 21: Kurixalus appendiculatus from Lata Tembaka. 22: Polypedates macrotis from Gunung Tebu.

and chest and belly whitish and usually without spots.

All specimens from Gunung Tebu were located at night sitting on leaves and branches of low to medium level vegetation along slow flowing streams. This species was commonly heard calling at night and was common in disturbed areas near water. The specimen from Lata Tembaka was found on a leaf $1 \mathrm{~m}$ above the ground. Dring (1979) and Grismer (2011a) had similar observations. The specimens from Gunung Lawit were found along the stream near camp.

Polypedates macrotis (Boulenger, 1891) (Figure 22)

Lata Tembaka: LSUHC 9799, 2 July 2010. Below 600 m on Gunung Tebu. LSUHC 11287, 2 July 2010.

Two male specimens (LSUHC 9799, SVL $63 \mathrm{~mm}$; LSUHC 11287, SVL $60 \mathrm{~mm}$ ) agree with Berry's (1975) diagnosis in having vomerine teeth; fingers webbed at the base; back smooth; webbing not reaching the disk of the fourth finger; no flap of skin on outer margins of limbs; and a broad dark brown stripe from eye to beyond axilla, covering the tympanum. LSUHC 11287 has brown spots on the belly and ventral side of thighs; and brown blotches on the throat.

LSUHC 9799 was collected from a leaf about 1 meter off the ground near the edge of the river during a rainstorm. Several other individuals were seen nearby. Dring (1979) had similar observations. LSUHC 11287 was found at night on a bathroom wall.

Kurixalus appendiculatus (Günther, 1858) (Figure 21) Lata Tembaka: LSUHC 9887, 6-7 September 2011.

A single male specimen (SVL $48 \mathrm{~mm}$ ) agrees with Berry's (1975) description of Peninsular Malaysian specimen in having vomerine teeth present; fingers webbed towards the base; back smooth and slightly granular lacking large tubercles or asperites; broad webbing not reaching disk of fourth finger; a free flap of skin along outer margin of forearm and foot; flaps of skin below vent and on forearm, sides of body and foot distinctly scalloped; and no conspicuous, black spot in axilla.

The individual was found at night sitting on a leaf 5 $m$ off the ground near the edge of the river. Dring (1979) collected most specimens at night from Sungai Kelebang in shrubby disturbed areas and occasionally from areas with swampy or shallow pools.

Theloderma horridum (Boulenger, 1903) (Figure 23)

Over $640 \mathrm{~m}$ on Gunung Tebu: LSUHC 10878, 2 


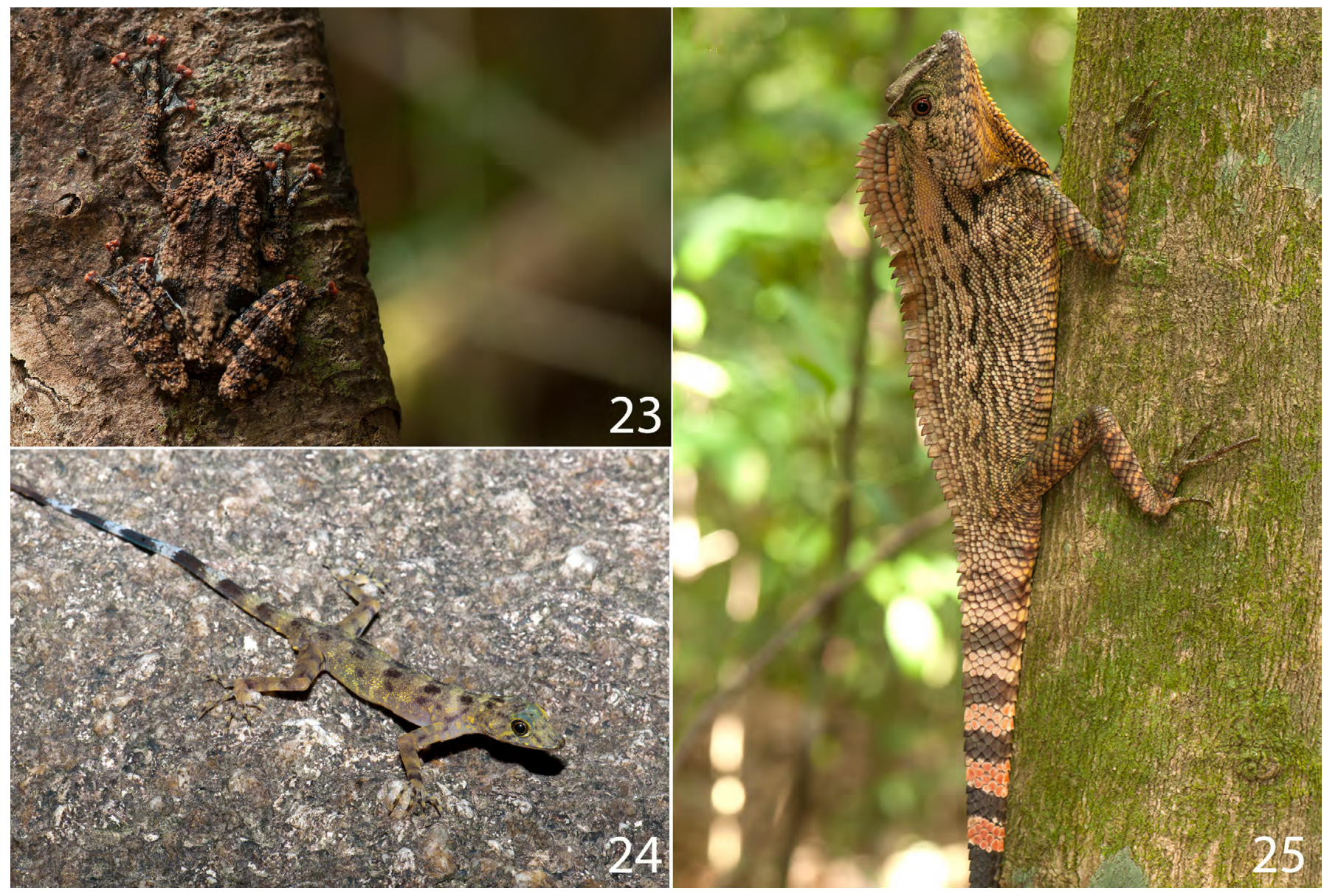

Figures 23-25: A frog and lizards from Gunung Tebu and Lata Belatan. 23: Theloderma horridum from Gunung Tebu. 24: Cnemaspis argus from Lata Belatan. 25: Gonocephalus abbotti from Gunung Tebu.

September 2012. LSUHC 11175, 30 June 2013.

Two adult females (SVL $44-45 \mathrm{~mm}$ ) match Grismer's (2011a) diagnosis of Malaysian specimens collected from Pulau Tioman (LSUHC 4404, 4415, 4678, 5417) in having a stocky body with a flat, wide head, and protuberant snout; large eyes about same size as tympanum: moderately sized limbs; tips of digits expanded to form truncate, square disks each with a circum-marginal groove; fully webbed toes; fingers webbed $1 / 2$ distance to disks; and rough, turberculate skin.

Both specimens were collected at night in dense primary forest. LSUHC 11175 was located resting vertically $4 \mathrm{~m}$ above the ground on a tree trunk. Although both specimens were collected 10 months apart, both were from the same tree. Dring (1979) found this species at 43 meters near the Sungai Kelebang in thick roadside vegetation at night.

\section{Squamata \\ Lizards}

\section{Family Agamidae}

\section{Aphaniotis fuscus (Peters, 1864)}

Lata Tembaka: LSUHC 9905, 5-6 September 2010. Lata Belatan: LSUHC 11189, 1 July 2013. USMHC 1082, 12 July 2012. Base of Gunung Lawit: LSUHC 8297, 98, 22 June 2012.
Two adult females (LSUHC 9905, SVL $62 \mathrm{~mm}$ and LSUHC 11189, SVL $65 \mathrm{~mm}$ ) and two specimens from Gunung Lawit are in accord with Grismer's (2011b) diagnosis and Malaysian specimens (LSUHC 4557-58, 4627-28, 4651, 4656,4656-57, 466o, 4797, 5407, 5408, $5428,5433,5435,5440,5448,5451-52,5456,6243,6269$, $6269,6281,6297,6299,6300,6302-03$ ) in having a small body lacking a high nuchal crest; small irregular scales on the head; thin body, triangular in cross section; eyelids present; limbs long and thin; digits unmodified; tympanum covered in scales, slightly visible; and body scales weekly keeled. Body brownish in females with small, lighter markings; and gums less blue than males.

LSUHC 9905 was collected on a twig three $m$ above the ground while resting at night. LSUHC 11189 was found sleeping on a leaf at night at approximately the same height. Dring (1979) collected individuals from similar habitats in disturbed forest at Sungai Kelebang. Grismer (2011b) had similar natural history notes. LSUHC 8297 and 98 were collected along stream near base camp on Gunung Lawit.

\section{Calotes emma Gray, 1845}

Lata Tembaka: LSUHC 8318, 25 June 2012.

A subadult male (SVL $88 \mathrm{~mm}$ ) matches Grismer's 
(2011b) diagnosis of Peninsular Malaysian specimens by having a moderately long tail, approximately 2.8 times SVL; a weak laterally compressed body; dewlap; dorsal scales keeled, those on flanks oriented dorsoposteriorly; patagia absent; ante-humeral fold present; vertebral crest composed of elongate, lanceolate scales extending from occiput to just beyond the base of the tail; long, epidermal spine behind orbit; two clusters of 3-5 elongate, epidermal spines above tympanum; tympanum naked; and femoral pores absent. Although present, the dewlap in this specimen was small indicating its immaturity.

We collected this specimen during the day from a brush pile in a disturbed area. Grismer (2011b) noted that this species is more of a scansorial, forest dwelling species than Calotes versicolor and is less commonly seen in disturbed habitats.

\section{Calotes versicolor (Daudin, 1802)}

Lata Belatan: USMHC 1086, 13 July 2012.

An adult female (SVL 92mm) matches Grismer's (2011b) diagnosis of Peninsular Malaysian specimens in having a laterally compressed body; dewlap present; dorsal scales keeled, those on flanks oriented dorsoposteriorly; patagia absent; antehumeral fold absent; vertebral crest composed of enlarged, lanceolate scales extending from occiput to just beyond base of tail; no epidermal spine behind orbit; two clusters of one or two elongate, epidermal spine above tympanum; tympanum naked; femoral pores absent.

This specimen was collected during the day and we found it positioned head up with its body oriented vertically on a small tree along the road. It was gravid and carrying seven eggs.

\section{Draco formosus Boulenger, 1900}

Lata Belatan: LSUHC 10979, USMHC 1078, 1079, 11 July 2012. Lata Tembaka: LSUHC 9874-9877; 9893, 9895-96, 6-7 September 2012.

A series of six males (SVL 98-108 $\mathrm{mm}$ ) and four females (SVL 84-99 mm) match Grismer's (2011b) diagnosis of Peninsular Malaysian specimen in having a relatively thin body with thin limbs; nuchal crest present in males; enlarged scales on distal portion of dewlap; small irregular scales on top of head; no enlarged pointed scales posterior to orbit; external nares directed dorsally; body not laterally compressed; rows of isolated, enlarged spinose scales on posterior portion of flanks; eyelids present; digits unmodified; tympanum naked; body scales nearly granular; patagium composed of a sheath of skin covering five elongated ribs forming a patagium; body greenish with faint, dark transparent bands; dewlaps in males transparent with an expanded scaly tip, much smaller and transparent in females; 4-6 rows of elongate, dark bands on a grayish patagium; on outer edge of patagium red.
All individuals were collected during the day approximately 3-4 $\mathrm{m}$ up on moderately spaced trees. LSUHC 9874, 9875 and USMHC 1079 were gravid females. Dring (1979) reported similar observations and collected individuals from both Sungai Kelebang and Gunung Lawit.

\section{Draco melanopogan Boulenger, 1887}

Lata Tembaka: LSUHC 9879-81, 7 September 2010. Lata Belatan: LSUHC 10969, 10973, USMHC 1043, 1044, July 2012. Gunung Tebu: LSUHC 11205, 30 June 2013.

A series of four adult males (USMHC 1043, 1044; LSUHC 10973, 11205) and four adult females (LSUHC 9879-81, 1069) agree with Grismer's (2011b) diagnosis of Peninsular Malaysian specimen in males reaching $85 \mathrm{~mm}$ SVL; females reaching $93 \mathrm{~mm}$ SVL; tail 1.7-2.0 times SVL; body dorsoventrally compressed; dewlap bearing slightly enlarged scales distally, narrow distally; dorsal scales smooth; patagium usually bearing five ribs; antehumeral fold grading anteriorly into lappets; no vertebral crest on body; no vertebral fold on neck; no caudal crest; no tubercles anterior to tympanum; no tubercles in occiput; tympanum nearly completely covered by smooth scales; femoral pores absent; and nostrils directed dorsally.

This species was collected during the day approximately 3-4 $\mathrm{m}$ above ground in an area of moderately spaced trees in both primary forest and slightly disturbed habitat. Males often were observed flashing their black dewlaps and individuals were seen gliding from tree to tree early in the morning and in the late afternoon. Dring (1979) had similar observations and collected specimens from both Gunung Lawit and Sungai Kelembang.

\section{Draco sumatranus Schlegel, 1844}

Lata Tembaka: LSUHC 9898, 6-7 September 2010. Lata Belatan: LSUHC 10909, 3 September 2012. LSUHC 11181, 30 June 2013.

Three adult females (SVL $72-77 \mathrm{~mm}$ ) agree with Grismer's (2011b) diagnosis of Malaysian specimens (LSUHC 3777-78, 3837-39, 3899, 3980, 4555-56, 460o, $5403-05,5491,6204,6228,8037)$ in having body dosoventrally compressed; dewlap tapered and rounded distally; dorsal scales weakly keeled; patagium bearing six ribs; antehumeral fold grading anteriorly into lappets; vertebral crest absent on body; vertebral crest on nape composed of enlarged scales; no caudal crest; weekly keeled tubercle anterior to tympanum; short, single conical tubercle on occiput; tympanum nearly completely covered by large, raised scale; femoral pores absent; and nostrils directed laterally.

LSUHC 9898 was collected $2 \mathrm{~m}$ up on the trunk of a tree during the day and LSUHC 10909 was found at night sleeping on the wall of a chalet. While walking on a trail near a river during the day, LSUHC 11181 was found on 
the ground near tree bases and small rocks. We suspect it was searching for a spot to lay its eggs. LSUHC 10909 and 11181 were carrying two eggs. Grismer (2011b) reported similar observations.

\section{Draco quinquefasciatus Hardwicke \& Gray, 1827}

Lata Tembaka: LSUHC 8829, 12 March 2008. LSUHC 8319: 24 June 2012.

Two gravid females (SVL 105-110mm) closely match Grismer's (2011b) diagnosis of Peninsular Malaysian specimen by having dorsoventrally compressed body; dorsal scales smooth; patagium bearing six ribs; antehumeral fold grading anteriorly into lappets; no vertebral crest on body; vertebral fold on neck; no caudal crest; no tubercles anterior to tympanum; no tubercles on occiput; tympanum covered by scales; femoral pores absent; and nostrils directed dorsally. Similar to males, we found that females also had slightly enlarged scales on the distal portion of the outer dewlaps.

The two gravid females were collected from approximately $3 \mathrm{~m}$ up on tree trunks during the day. LSUHC 8319 had three large eggs and appeared to be near the end of her term. LSUHC 8829 had a small hole in its patagium beneath the fourth rib. Grismer (2011b) reported similar behavior and observed gravid individuals at Lata Tembaka during September. Most specimens collected by Grismer (2011b) had four eggs. Dring (1979) collected one specimen at night while sleeping on the trunk of a tree at Sungai Kelebang.

\section{Gonocephalus abbotti Cochran, 1922 (Figure 25)}

580-800 $\mathrm{m}$ on Gunung Tebu: LSUHC 10906, 2 September 2012.

An adult male (SVL $174 \mathrm{~mm}$ ) mostly agrees with Grismer's (2011b) diagnosis in having no spines above the eye; a strongly elevated, prominent, superciliary ridge continuous with the canthus rostralis and forming a sharp angle above posterior margin of the eye; tympanum naked; dewlap present; body laterally compressed, triangular in cross section; dorsal, body scales small, smooth and bearing a row of enlarged, smooth, widely spaced, dorsolateral scales; ventral scales smooth; patagia absent; high, continuous, vertebral crest with an even dorsal profile tapering smoothly from occiput to anterior portion of tail; dorsal crest composed of three rows of enlarged, flattened, separated scales; femoral pores absent; and tail 1.4-1.5 times the SVL. This specimen exceeds the maximum SVL of $163 \mathrm{~mm}$ reported for males by Grismer (2011b).

We collected this exceptionally large specimen from $3 \mathrm{~m}$ up the trunk of a tree at night. Grismer (2011b) observed that this species occurs from $200-1,000 \mathrm{~m}$ in elevation and is most commonly found in dense forest near water. Dring (1979) listed this species as G. chamaeleontinus and collected a specimen on a twig approximately $1 \mathrm{~m}$ above the ground from primary hillside forest $790 \mathrm{~m}$ on Gunung Lawit.

\section{Gonocephalus bellii (Duméril \& Bibron, 1837)}

Lata Tembaka: LSUHC 9889, 9890, 6 and 7 September 2010. Lata Belatan: LSUHC 10836, 31 September 2012. USMHC 1056, 9 July 2012. Over $580 \mathrm{~m}$ on Gunung Tebu: LSUHC 10880-83, 10907, 2 September 2012. LSUHC 11208, 11223-27, July 1 and 22013.

A series of six adult females (LSUHC 9890, 10880-81, 11225-26, USMHC 1056; SVL 55-215 mm), eight adult males (LSUHC 9889, 10836, 10880, 10882-83, 10907, 11224, 11227; SVL 103-307 mm) and one hatchling (LSUHC 11223, SVL $41 \mathrm{~mm}$ ) are in accord with Grismer's (2011b) diagnosis of Peninsular Malaysian specimen with adult males reaching $150 \mathrm{~mm}$ SVL and adult females reaching $120 \mathrm{~mm} \mathrm{SVL}$; no spines above eye; low supercilliary ridge continuous with canthus forming a rounded angle above posterior margin of eye; periphery of tympanum covered by small scales; dewlap present; body somewhat laterally compressed; dorsal scales spinose, intermixed with larger, keeled scales on flanks; ventral scales keeled; patagia absent; vertebral crest composed of separate, elongate, lancelote scales beginning at occiput and abruptly tapering at base of tale; femoral pores absent; and tail 2.0-3.0 times SVL. We noted varying degrees of color pattern variation among individuals mostly based on age and gender as mentioned by Grismer (2011b). Dewlap coloring was more intense in large adult males and spines of the vertebral crest were much more prominent than in females. The hatchling displayed traces of slight coloration on the dewlap and no vertebral crest.

All specimens were collected at night while sleeping on thin twigs, branches, and leaves at approximately 3 $m$ off the ground. At Gunung Tebu, we observed several individuals sleeping on vegetation during heavy rains. We suspect this species chooses to rest on thin branches and twigs to more easily sense vibrations caused from a potential predators. Dring (1979) collected this species at $790 \mathrm{~m}$ on Gunung Lawit while the individual rested on a twig about $1 \mathrm{~m}$ off the forest floor. Grismer (2011b) had similar observations.

\section{Gonocephalus grandis (Gray, 1845)}

Lata Belatan: USMHC 1066, 11 July 2012.

The juvenile specimen (SVL $37 \mathrm{~mm}$ ) agrees with Grismer's (2011b) diagnosis of this species. No spines above eye; low superciliary ridge continuous with canthus and forming a low, rounded angle above posterior margin of eye; tympanum naked; dewlap present; body somewhat laterally compressed, triangular in cross-section; patagia absent; femoral pores absent and tail 3 times SVL.

The specimen was collected from low vegetation 
along the river during the day. Dring (1979) collected this species from vegetation around Sungai Keleband and neighboring streams.

\section{Family Gekkonidae}

\section{Cnemaspis argus Dring, 1979 (Figure 24)}

Lata Belatan: LSUHC 10834-5, 31 August 2012. USMHC 1059, 1081, 1089, 11 July 2012. Near base camp on Gunung Tebu: LSUHC 11202, 11209, 11210, 1 July 2013. Near the base of Gunung Lawit: LSUHC 8304, 23 June, 2012.

Six adult males (LSUHC 8304, 10834-35, 11202, 11209, USMHC 1059, SVL 51-62 mm), one subadult male (USMHC 1089, SVL 45mm) and two adult females (LSUHC 11210, USMHC 1081, SVL 58-66 mm) closely agree with Dring (1979) from Gunung Lawit in having round pupils; a weak to absent canthal ridge; 15 supralabials; smooth forearm scales; keeled central and subcaudal scales; keeled dorsal tubercles; median subcaudal scale row not enlarged; digits slender; 37-39 subdigital lamellae on the fourth toe; tail 1.5 times SVL; no dark shoulder patch enclosing a light oculus; large, black blotches on body; and dark, caudal bands present. LSUHC 11202 differed from Grismer's (2011b) diagnosis in having six as opposed to 10 precloacal pores.

LSUHC 11209-10 was found crawling upside down in a granite cave near a stream. LSUHC 11202 was collected on a granite bolder in the forest. Dring (1979) reported similar observations from a specimen up 790 m on Gunung Lawit. Dring (1979) reported specimen from Gunung Lawit at $790 \mathrm{~m}$ in elevation however, we collected on adult male (LSUHC 8304, SVL $57 \mathrm{~mm}$ ) from $230 \mathrm{~m}$ at the base of Gunung Lawit and several at Lata Belatan. We suggest that this species is associated with granite boulders wherever they may be and is not strictly and upland species.

\section{Cyrtodactylus consobriunus (Peters, 1871)}

Lata Tembaka: LSUHC 9908, 5 and 6 September 2010. At Punca Air, Gunug Tebu: LSUHC 11201, 1 July 2013. Base of Gunung Lawit: LSUHC 8286, 8287, 22 June 2012.

A gravid female (LSUHC 11201, SVL $77 \mathrm{~mm}$ ) and two specimens (LSUHC 8286, 8287) from Gunung Lawit mostly agree with Grismer's (2011b) diagnosis of Peninsular Malaysian specimen in having elliptical pupils; small, low, conical, smooth tubercles from nape to base of tail; 45-51 ventral scales across belly; transversely enlarged, median, subcaudal scales; proximal subdigital lamellae transversely expanded; 18--23 subdigital lamellae on fourth toe; abrupt transition between the large, posterior and small, ventral femoral scales; no enlarged pore-bearing femoral or precloacal scales; a faint, lightly colored reticulate pattern on top of head; and body banded. LSUHC 11201 differed from Grismer's (2011b) description in having small tubercles scattered unevenly on the forelimbs instead of large, conical tubercles. LSUHC 9908 was not examined.

The specimen from Lata Tembaka was collected from a tree stump at night. The Gunung Tebu, specimen was carrying two eggs and found about $2 \mathrm{~m}$ up on the base of a tree near water. Dring (1979) had similar observations from a specimen collected from secondary forest at Sungai Kelebang. Grismer (2011b) also had similar observations and noted that this species can be found within cracks and hollows of rock walls and fallen logs. It is common to find multiple individuals on the same tree. LSUHC 8286 and 87 were found on the base of trees near camp on Gunung Lawit.

Cyrtodactylus tebuensis Grismer, Anuar, Muin, Quah, \& Wood, 2013 (Figure 26)

580-80o meters on Gunung Tebu: LSUHC 10851-52, 10901-03, 1 and 2 September 2012. Near base camp on Gunung Tebu: LSUHC 11182, 11191-99, 30 June-1 July 2013.

A series of three juveniles (LSUHC 11191-93, SVL 32-39 mm); three subadults (LSUHC 10851, 11195, 11198, SVL 58-59 mm); and five adults (LSUHC 10852, 10901, 11182, 11194, 11199, SVL 72-85 mm) agree reasonably with Grismer et al.'s (2013) diagnosis in having large, conical, keeled body tubercles; tubercles present on the top of the head, occiput, nape, and limbs that extend posteriorly to past the base of the tail; no transversely enlarged, medium subcaudal scales; proximal subdigital lamellae transversely expanded; 17-21 subdigital lamellae on the fourth toe; abrupt transition between posterior and ventral femoral scales; enlarged femoral scales; no precloacal or femoral pores; no precloacal groove; and four wide dark brown stripes running down the body. Additional specimens require modifications of Grismer et al.'s (2013) diagnosis. An adult (LSUHC 11194) was $85 \mathrm{~mm}$ instead of between 73.1-84.1 mm and several specimens had 3-7 fewer than 43-51 ventral scales. Not mentioned by Grismer et al. (2013) was the presence of color pattern variation between individuals. Rather than four dark stripes running down the body, some specimens (LSUHC 11182, 11192-93, 11195) had thick, uneven, dark-colored blotches running down its back that appeared to be dark stripes partially merging together. Some were spotted (LSUHC 11182, 11195) as well.

Individuals were collected at night from leaves and roots near to the forest floor and on the base of trees on nights that it was not raining.

Crytodactylus timur Grismer, Wood, Shahrul, Quah, Muin, Maketab, Chan, Sumarli, Loredo \& Heinz, 2014

Gunung Tebu: LSUHC 10886, 11183, 11184, 11185, 11207, 1-2 July 2013. 

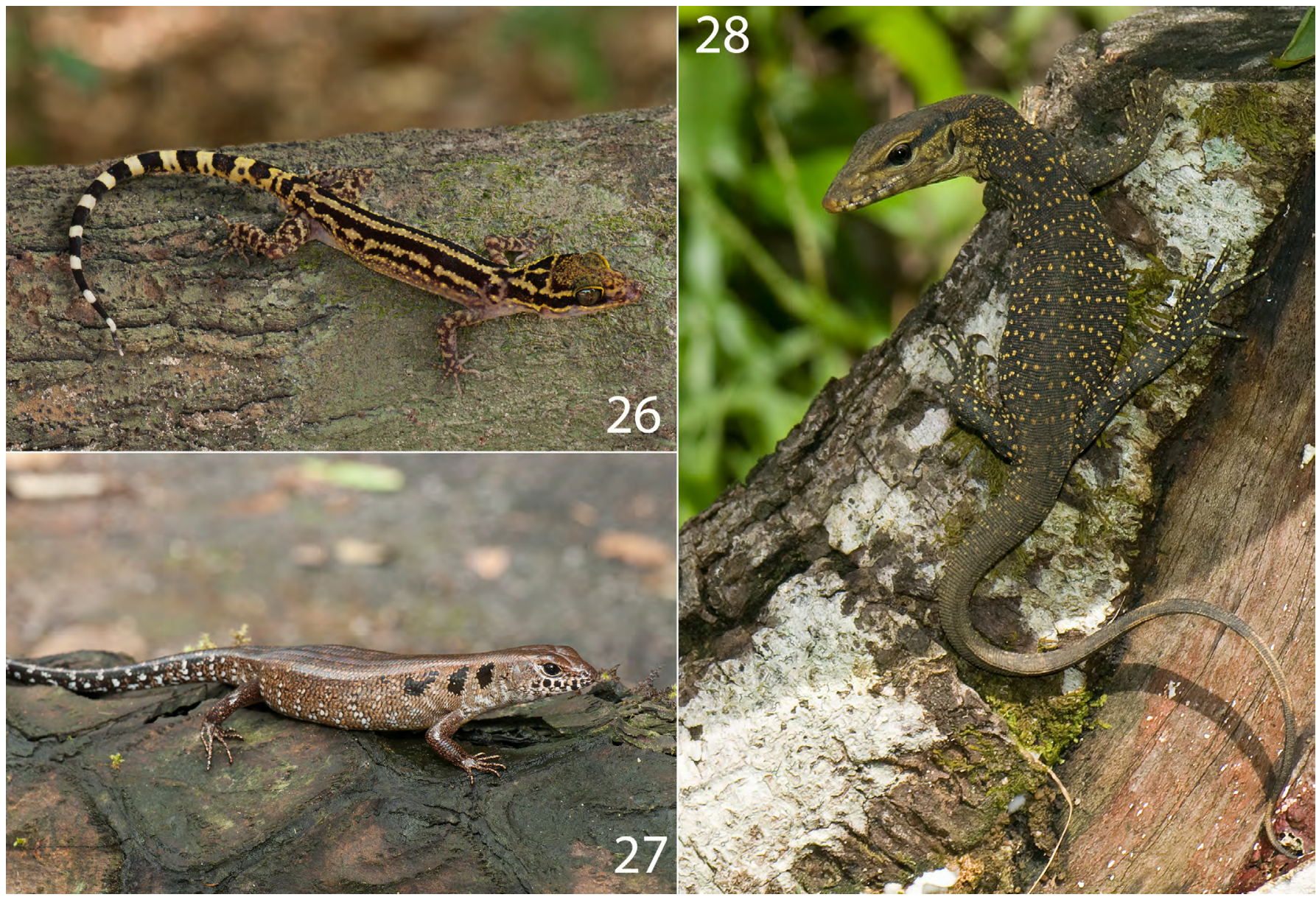

Figures 26-28: Lizards from Lata Belatan and Gunung Tebu. 26: Cyrtodactylus tebuensis from Gunung Tebu. 27: Sphenomorphus praesignus from Gunung Tebu. 28: Varanus nebulosus from Lata Belatan.

Cyrtodactylus timur can be differentiated from all other species of Cyrtodactylus by having 10-12 supralabials; 8-10 infralabials; weak body tuberculation; no tubercles on ventral surface of forelimbs, gular region, or in ventrolateral body folds; 38-43 paravertebral tubercles; 21-24 longitudinal tubercle rows; 31-40 ventral scales; 21-25 subdigital lamellae on fourth toe; 21 or 22 femoroprecloacal pores; deep precloacal groove; four dark dorsal body bands; body band/interspace ratio 1.00-1.25; no scattered white tubercles on dorsum; 8-10 dark caudal bands on original tail; white caudal bands nearly immaculate; and a maximum SVL of $120.5 \mathrm{~mm}$.

Specimens were collected at night in primary hill dipterocarp forest in the vicinity of a rocky stream between $640 \mathrm{~m}$ and $700 \mathrm{~m}$ in elevation. Lizards were most common on the granite boulders along the stream but others were seen on the bases of trees and one individual was observed on an earthen bank. A small juvenile (LSUHC 10886, SVL $60.3 \mathrm{~mm}$ ) was found on a twig at the base of a large tree deep in the forest and away from the stream.

\section{Cyrtodactylus quadrivirgatus Taylor, 1962}

Lata Belatan: USMHC 1029, 9 July 2012. Gunung Tebu: LSUHC 10853.
Two females (USMHC 1029, SVL 6omm; LSUHC 10853 , SVL $75 \mathrm{~mm}$ ) agree with Grismer's (2011b) diagnosis in having pupils elliptical; moderately sized, conical, keeled, body tubercles; tubercles occurring on occiput, forelimbs, hinds limbs, extending to beyond base of tail; 35-42 ventral scales across belly, no transverly enlarged, median subcaudal scales; proximal, subdigital lamellae enlarged, square; 18-20 subdigital lamellae on fourth toe; abrupt transition between small, posterior and large, ventral femoral scales; emlarged femoral and precloacal scales; no femoral pores; o-4 contiguous, pore bearing precloacal scales; no precloacal groove or depression; no paired, dark, semilunar-shaped blotches on upper nape; wide, dark, ventrolateral stripe on flanks confluent with a wide, dark, postorbital stripe, rarely broken on neck; no white recticulum on head; dark botches and/or stripes on body.

USMHC 1029 was found at the base of a tree along the river at night. And LSUHC 10853 was also found at the base of a tree.

\section{Gehyra mutilata (Wiegmann, 1834)}

Lata Tembaka: LSUHC 9888, 6 and 7 September 2010. Near base camp on Gunung Tebu LSUHC 11200, 1 July 2013. Lata Belatan: USMHC 1030, 9 July 2012. 
An adult male (LSUHC 9888, SVL $57 \mathrm{~mm}$ ) and a gravid female (LSUHC 11200, SVL $52 \mathrm{~mm}$ ) are in accord with Grismer's (2011b) diagnosis of Malaysian specimens (LSUHC 6231-5, 4677, 4839, 5495, 5563) in having a small body with a weakly, dorsoventrally compressed head and body; small granular scales on head; tympanum naked; eyelids absent; pupils vertical; small fringe of skin extending from posterior surface of hind limbs, short and wide hands and feet slightly webbed; subdigital lamellae expanded; inner fingers and toes usually lacking claws; body scales granular; no fringes of skin on body; weak , denticulate fringe on tail; caudal spines absent; and precloacal and femoral pores present in males.

The gravid female was carrying two eggs and was collected on the base of a tree at night near Punca Air. LSUHC 9888 was found on the wall of a building at night. Dring (1979) collected specimens under the bark of a dead tree in secondary roadside vegetation at Sungai Kelebang. Grismer (2011b) reported finding specimens on a multitude of substrates and microhabitats in both primary forest and disturbed areas.

\section{Gekko monarchus (Schlegel, 1836)}

LSUHC 11286: Lata Belatan, July 32013.

An adult male (LSUHC 11286, SVL $95 \mathrm{~mm}$ ) agrees with Grismer's (2011b) diagnosis of Peninsular Malaysian specimen and mostly agrees with three Malaysian specimen from Pulau Tioman (LSUHC 5509, 5215, 5257) in having a small to medium sized body with a dorsoventrally compressed head and body; granular scales on head; tympanum naked; eyelids absent; pupils vertical; digits with expanded, subdigital lamellae; inner finger and toe lacking claws; body scales granular, interspersed with large tubercles; no fringes of skin on body or tail; caudal spines absent; precloacal and femoral pores present in males; and body and limbs beige to dark brown with small, paired, dark paravertebral spots on body. When compared to LSUHC 5509 from Pulau Tioman, LSUHC 11286 appears to have less prominent femoral pores and has weaker paravertebral spots on the body.

This specimen was collected at night on a chalet wall and was white in color. Its tail was regenerated and we postulate that it was missing four of its outer digits due to a predator or rival male. Grismer (2011b) reported similar observations.

\section{Gecko smithii Gray, 1842}

At camp on Gunung Tebu: LSUHC 11206, 1 July 2013.

A single female (SVL $149 \mathrm{~mm}$ ) generally matches Grismer's (2011b) description of specimens from Peninsular Malaysia in having vertical pupils; large, low, conical, smooth, body tubercles extending from nape and side of head to base of tail; $3-13$ longitudinal rows of dorsal tubercles on body; no tubercles on brachia; no skin flaps on body; first digit of hands and feet not vestigial but clawless; undivided subdigital lamellae expanded throughout length of digit; 23-26 subdigital lamellae on fourth toe; rostral grooved, not contacting nostrils; large, white, transversely arranged spots on body; and metallic green iris. Not mentioned in Grismer's (2011b) diagnosis was that females also have 7-17 contiguous, pore-bearing precloacal scales.

The individual was collected on a tree in camp at night. Other Gecko smithii could be heard calling in the forest from midday to afternoon. Grismer (2011b) had similar observations and noted that this species can be found all types of primary and secondary forest including peat swamps. This species is almost always found on tree trunks or large rocks, and rarely on small branches or leaves unless a juvenile.

\section{Hemidactylus craspedotus (Mocquard, 1890)}

Lata Belatan: LSUHC 10838, 31 August 2012.

An adult male (SVL $60 \mathrm{~mm}$ ) is in accord with Grismer's (2011) diagnosis of specimens from Peninsular Malaysia in having vertical pupils; rounded tubercles extending from rostrum to base of tail; 10-16 longitudinal rows of dorsal tubercles on body; no tubercles on brachia or tail; wide ventrolateral flaps of skin on neck, body, tail, and posterior margins of limbs; first digit of hands and feet well-developed and bearing a claw; wide, transversely expanded, subdigital lamellae; eight or nine expanded subdigital lamellae on fourth toe; digits nearly fully webbed; 32-49 pore-bearing femoral and precloacal scales in males separated medially by 2-6 precloacal scales lacking pores; caudal tubercles absent; and rostral contracting nostrils.

This specimen was found crawling on the base of a tree at night. Grismer (2011b) reported that this species is almost exclusively found on tree trunks in lowland and hill depterocarp forest, coconut plantation, and disturbed areas.

\section{Hemidactylus frenatus Duméril \& Bibron, 1836}

Lata Belatan: USMHC 1045, 9 July 2012.

An adult male specimen (SVL52mm) agrees with Grismer's (2011b) diagnosis of specimens from Peninsular Malaysia in having pupil vertical; dorsal scales granular; tubercles absent; no ventrolateral flaps of skin anywhere on body, limbs or tail; first digit of hands and feet short; claw extending past lamellar pad; wide, transversely expanded, divided, subdigital lamellae; nine or 10 expanded, subdigital lamellae on fourth toe; webbing absent; 26-38 contiguous, porebearing femoral and precloacal scales. Spinose tubercles on the tail were not observed in this specimen because it had a regenerated tail.

This Specimen was collected on a wall of a building 
at night supporting Grismer's (2011b) account for this species and its presence as a common human commensal.

\section{Hemidactylus platyurus (Schneider, 1792)}

Lata Belatan: USMHC 1055, 10 July 2012.

A single adult male (SVL $61 \mathrm{~mm}$ ) fits Grismer's (2011b) description of this species in having pupil vertical; dorsal scales granular; tubercles absent; narrow, ventrolateral flaps of skin on body, posterior margins of limbs, and tail; no flaps on neck; first digit of hands and feet well developed and bearing a claw; wide, transversely expanded, divided, subdigital lamellae; six to nine expanded, subdigital lamellae on fourth toe; digits nearly one-half webbed; $26-40$ pore-bearing femoral and precloacal pores separated medially by one or two precloacal scales lacking pore; caudal tubercles absent. The specimen is missing its third toe on the left forelimb and the tip of the tail is regenerated.

Specimen was collected on the wall of a chalet at night. Similar to the preceding species, it is also a human commensal that is often found residing on buildings as noted by Grismer 2011b.

Hemiphyllodactylus tehtarik Grismer, Wood, Anuar, Muin, Quah, McGuire, Brown, Tri, and Thai, 2012

Gunung Tebu: LSUHC 10904, 2 September 2012

Known only from holotype and is separated from all other species of Hemiphyllodactylus by the unicolour rust-orange dorsal pattern, absence of white postorbital spots, and a lamellar foot formula of 3-4-54. It is further separated from all other congeners by: the unique combination of a maximum SVL of 40.4 $\mathrm{mm}$ in females (males unknown); eight chin scales, extending transversely from unions of second and third infralabials, and the posterior margin of mental; enlarged postmental scales; five circumnasal scales; three scales between supranasals (= postrostrals); 11 supralabials; 10 infralabials; 18 longitudinally arranged dorsal scales at midbody contained within one eye diameter; 12 longitudinally arranged ventral scales at midbody, contained within one eye diameter; lamellar formula on hand 3-3-3-3; no precloacal or femoral pores in females (males unknown); postsacral mark orange and bearing anteriorly projecting arms; and ceacum and oviducts unpigmented.

Holotype was collected at night on the leaf of a palm tree (Licuala sp.), approximately $1 \mathrm{~m}$ above the ground, along the edge of a small stream coursing through large granite boulders. Refer to the species description for more details.

\section{Ptychozoon kuhli (Stejneger, 1902)}

Lata Belatan: LSUHC 11285, 3 July 2013.

A single adult female (SVL $96 \mathrm{~mm}$ ) agrees with Grismer's (2011b) diagnosis of specimens from
Peninsular Malaysia having vertical pupils; head, body, limbs, and tail covered in flat, juxtaposed scales; low, widely dispersed tubercles on flanks and posterior portion of body; elongate, postmental scales large claps of skin fringing outer margins of all regions of body (except rostrum, neck, and anterior margin of thigh); no predigital notch between first digit on hand on antebrachial skin fold; completely webbed hands and feet; first digit of hands and feet short, not vestigial, clawless; subdigital lamellae undivided, enlarged proximally, thin and transversely expanded distally; distal most lamellae angular; 24-24 subdigital lamellae on fourth toe; and terminal joint of digits arising from lamellar pad and extending beyond.

This specimen was collected at night from the roof of a pondok (hut). Grismer (2011b) reported usually finding this species on large trees in lowland and hill dipterocarp forest up to $800 \mathrm{~m}$ in elevation. This species can also be found on buildings or coastal vegetation.

\section{Ptychozoon lionotum Annandale, 1905}

Lata Tembaka: LSUHC 9891, 6 and 7 June 2010. Lata Belatan: LSUHC 11234-36: 3 July 2013. USMHC 1028, 1049, 1091: 9 July 2012.

A series of four gravid females (LSUHC 9891, 1123436, SVL 92-93 mm) mostly agree with Grismer's (2011b) diagnosis of specimens from Peninsular Malaysia in having vertical pupils; head, body, limbs, and tail covered in flat, juxtaposed scales; no body tubercles; enlarged postmental scales; large flaps of skin fringing the outer margins of all regions of body (expect rostrum, neck, and anterior margin of thigh); predigital notch between first hands and feet short, not vestigial, clawless; subdigital lamellae undivided, transversely expanded; distal most lamellae angular; and the terminal joint of digits arising from lamellar pad and extending beyond it.

All specimens had two eggs and were collected sitting head up at night between 1.5-5 $\mathrm{m}$ above the ground on trunks of trees. Dring (1979) collected an individual from 2-3 $\mathrm{m}$ up on a tree trunk in primary forest near the Sungai Petuang (250 $\mathrm{m}$ ) at night.

\section{Family Scincidae}

\section{Dasia olivacea (Gray, 1839)}

LSUHC 9878: Lata Tembaka, 7 September 2010.

A single subadult (SVL $87 \mathrm{~mm}$ ) matches Grismer's (2011b) diagnosis of specimens from Peninsular Malaysia in having a stout, oval shaped body in cross-section; dorsal scales smooth to faintly keeled; limbs moderate in length, overlapping when adpressed; lower eyelid scaly, lacking an enlarged, central disc; frontoparietals paired; supernasals and prefrontals very narrowly contacting on midline; scales on top of head outlined in black; and light body bands of juveniles thinner than dark body 
bands. This species exhibits color pattern variation based on geographic distribution. LSUHC 9878 had a deep, copper colored dorsum with a lime green ventrum as opposed to a tan colored ventrum and light green to mint colored dorsum found in coastal Dasia olivacea.

The specimen was collected during the day from 6 $\mathrm{m}$ up on the trunk of a tree in a disturbed area whole basking and was damaged during capture. Another individual was spotted during the day at Lata Belatan, but escaped into a tree hole, approximately $5 \mathrm{~m}$ above the ground.

\section{Eutropis macularia (Blyth, 1853)}

Lata Belatan: LSUHC 10826, 31 August 2012.

A female adult (SVL $46 \mathrm{~mm}$ ) with a broken tail is in accord with Grismer's (2011b) diagnosis of specimens from Peninsular Malaysia in having a stout body cylindrical in cross-section; dorsal scales with five prominent keels; keels not aligned from end to end from one scale to the next; limbs relatively short, overlapping when addressed; lower eyelid transparent; scaly, lacking a single enlarged, central disk; parietal scales smooth; fronto-parietals paired; prefrontal scales not contacting on midline; supranasals contacting on midline; no postnasal scale; no postmental scale; and a thin, white to light-brown, dorsolateral stripe extending from above eye to anterior portion of tail, becoming more diffuse one-half way down the body.

The female was found crawling in a grassy area during the day along the edge of a river in a disturbed area. This is in accord with Grismer's (2011b) description of this species' behavior and microhabitat.

\section{Eutropis multifasciata (Kuhl, 1820)}

Lata Belatan: LSUHC 10974, 9 Julyr 2012, USMHC 1083, 12 July 2012. LSUHC 11230, 3 July 2013. Lata Tembaka: LSUHC 9904, 5 and 6 September 2010. Base of Gunung Lawit: LSUHC 8277, 22 June 2012.

An adult male (LSUHC 9904, SVL $90 \mathrm{~mm}$ ), subadult female (LSUHC 10974, SVL $76 \mathrm{~mm}$ ), juvenile (LSUHC 11230, SVL $54 \mathrm{~mm}$ ), and a single specimen from Gunung Lawit closely match Grismer's (2011b) diagnosis of Peninsular Malaysian specimen by having a robust body, somewhat cylindrical in cross-section; dorsal scales with at least three prominent keels not aligned end to end from one scale to the net; limbs relatively short, barely overlapping when adpressed; lower eyelid transparent, scaly, lacking a single enlarged central disk; parietal scales smooth; frontoparietals paired; prefrontals widely contacting on midline; supranasals rarely contacting on midline; small, postnasal scale present; postmental scale present; and tail not twice as long as SVL. All specimens have three prominent keels on the dorsal scales. This species displays immense color pattern variation with little geographic correlation except when comparing island to peninsular species (Grismer 2011b). However, LSUHC 9904 and 11230 are nearly identical in color pattern in having a bronze colored dorsum with a thick dark-brown stripe running down the sides of the postorbital region and terminating near the base of the tail; small, white, scattered dots extend from behind the tympanum down the flanks; and a cream to tan colored ventrum.

This is a very common species and several individuals were observed during the day. At Lata Tembaka, skinks were commonly seen basking on logs and on the roots of trees during morning hours and foraging during other times of the day. In the upland areas of Gunung Tebu, skinks were less common but also seen foraging during the day. All individuals collected in these two sites were found at night sleeping in leaf litter and debris along trials on the forest floor at both localities. At Lata Belatan, skinks were caught during the day when they were out basking around forest trails or moving through leaflitter. Dring (1979) found individuals from Sungai Petuang $(250 \mathrm{~m})$ and Sungai Kelebang $(43 \mathrm{~m})$ in both primary and secondary forest. LSUHC 8277 was collected under a rock at night along a stream on Gunung Lawit.

\section{Lipinia vittigera (Boulenger, 1894)}

Lata Belatan: LSUHC 10887, 3 September 2012.

An adult individual (SVL $37 \mathrm{~mm}$ ) agrees with Grismer's (2011b) diagnosis of specimens from Peninsular Malaysia in having a small, elongate, cylindrical body and pointed snout; eyelids present; pupils round; digits unmodified; body scales flat, imbricate, and smooth; body and limbs dark brown to black; wide, yellow stripe extends from tip of snout to base of tail; yellowish dorsolateral stripes present; yellow strip in postorbital region continuing along flanks to base of tail; and tail orange (in adults).

This specimen was collected during the day from a tree approximately $2 \mathrm{~m}$ above the ground as it was climbing up the tree. Grismer (2011b) reported similar observations and noted that individuals were found from at least $600 \mathrm{~m}$ in elevation.

Sphenomorphus praesignus (Boulenger, 1900) (Figure 27) Near the summit of Gunung Tebu (approximately 1,000 m): LSUHC 11231, 2 July 2013.

A single adult male (SVL $115 \mathrm{~mm}$ ) agrees with Grismer's (2011b) diagnosis of specimens from Peninsular Malaysia and more specifically with specimens from Bukit Larut (LSUHC 9040, 9851-53) by having SVL reaching 110.0 $\mathrm{mm}$ in males; limbs overlapping when adpressed; 26-28 smooth, midbody scale rows; $65-67$ paravertebral scale rows; four supraoculars; prefrontals in contact; two undivided loreal scales; 20-25 smooth, subdigital lamellae beneath fourth toe; two enlarged preanal scales; body bands absent in adults; $3-7$ large, dark spots extending from side of neck onto flanks; no distinct, 
dark, dorsolateral stripe; and no light postorbital stripe.

LSUHC 11231 was found on a rainy night inside of a hollow log filled with water near the side of the trail. It retreated into the water where it stayed submerged for several minutes in an apparent attempt to escape collection. Dring (1979) collected an individual during the day on Gunung Lawit (128om) from beneath disturbed masses of moss at the base of a rotten tree stump.

\section{Family Varanidae}

Varanus nebulosus (Gray, 1831) (Figure 28)

Lata Belatan: LSUDPC 6456, 3 July 2013.

An adult was observed during the day in a tree near a disturbed area and another in the water near the shade. We observed a hatchling sitting in the fork of a large tree approximately $1.5 \mathrm{~m}$ above the ground near our chalets. Other specimens were seen foraging in the disturbed areas near the chalets. Monitor lizards also have been observed in disturbed areas at Lata Tembaka (LLG pers. obs.). Grismer (2011b) had similar observations. Dring (1979) reported seeing a juvenile on a dry crevice in the trunk of a fallen tree in secondary forest near Sungai Kelebang.
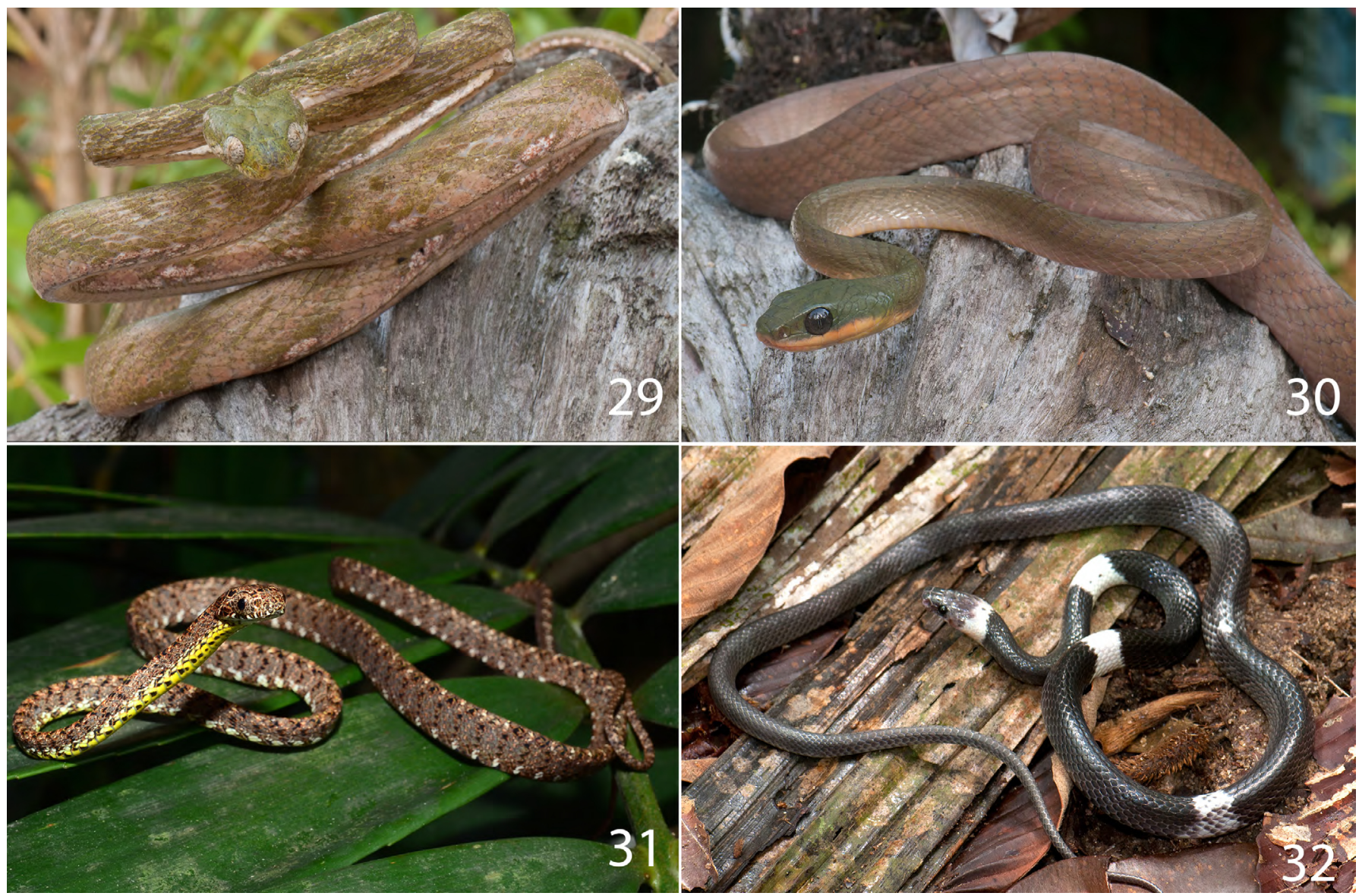

Figures 29-32. Snakes from Gunung Tebu and Lata Belatan. 29: Boiga drapezii from Gunung Tebu. 30: Boiga nigriceps from Gunung Tebu. 31: Boiga

jaspidea from Lata Belatan.32: Lycodon subsinctus from Lata Belatan.

\section{Snakes \\ Family Colubridae}

Boiga drapiezii (Günther, 1863) (Figure 29)

Lata Belatan: LSUHC 10837, 31 August 2012. Between base camp and peak on Gunung Tebu: LSUHC 11232, 2 July 2013. Over $800 \mathrm{~m}$ on Gunung Tebu: LSUHC 10884, 2 September 2012.

An adult male (SVL $1850 \mathrm{~mm}$ ) matches with Tweedie's (1983) diagnosis of this species and Grismer's (2011) diagnosis of specimens from Pulau Tioman in having a long, laterally compressed body, sharp vertebral ridge, and a greatly enlarged blunt, triangular head; head scales large and plate-like; eyes protuberant; pupils vertical; 19 rows of smooth, dorsal scale rows at mid-body with an enlarged vertebral row; 250-285 ventrals; 114-168 divided subcaudals; and anal plate entire. Color pattern variation in this species is extensive (Tweedie 1983), but it is not known how it correlates with geography. LSUHC 11232 has a greenish-grey body with ill-defined, dark-centered, lateral blotches with the darker areas between them being obscurely pale-centered (Tweedie 1983) whereas specimens from Pulau Tioman and Pulau Tinggi are more reddish (Grismer 2011a). LSUHC 10837 from Lata Belatan was also reddish in color. LSUHC 10884 was lost in transit.

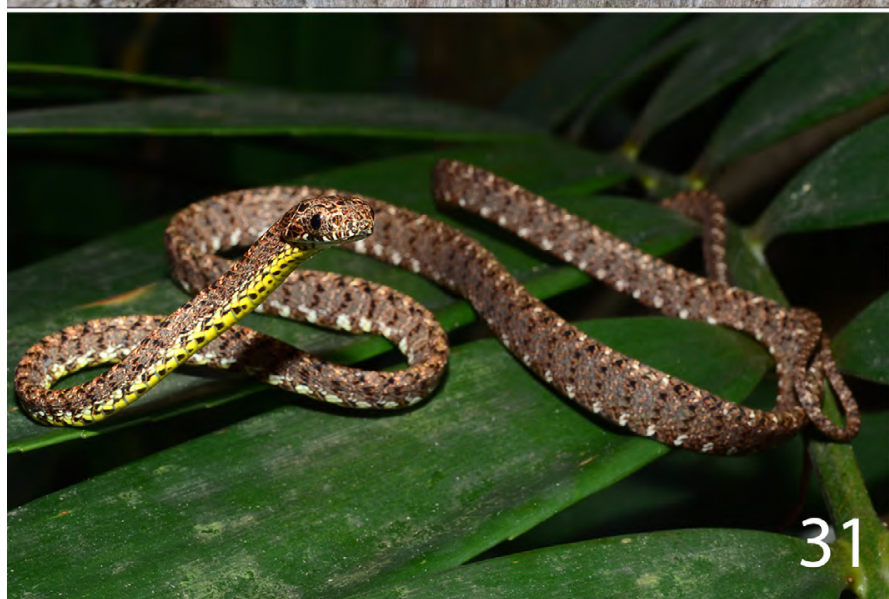


LSUHC 11232 was collected at night while moving across the ground during the rain. LSUHC 10837 was collected at night from a swampy area behind a chalet coiled up in rattan leaf $2.5 \mathrm{~m}$ above the ground. Dring (1979) collected a juvenile $1.5 \mathrm{~m}$ above ground on the front of a sessile palm in logged forest near the Sungai Kelebang (43 m). Grismer (2011b) reported this species being found in most forested areas about 1-3 $\mathrm{m}$ off the ground on vegetation or trees.

\section{Boiga nigriceps (Günther, 1863) (Figure 30)}

Below camp on Gunung Tebu: LSUHC 11233, 1 July 2013. An adult male (SVL $1750 \mathrm{~mm}$ ) agrees with Tweedie's (1983) diagnosis of this specimen and Grismer's (2011a) diagnosis of specimens from Pulau Tioman and Pulau Aur by having a body with a, sharp vertebral ridge, and an enlarged triangular head; head scales large and platelike; eyes large and protuberant; pupils vertical; 21 rows of smooth, dorsal scales at mid-body with an enlarged vertebral row; 240-265 ventrals; 140-154 divided subcaudals; and anal shield entire. The specimen was reddish brown with a dark green to grey head and light upper lip. It had two rows of faint black spots on its back and a thin, black postorbital stripe.

The individual was collected at night from $3 \mathrm{~m}$ up in a small tree. The next day it bit one of the collectors and chewed on her hand for approximately one minute before it could be removed. Her hand swelled to nearly 1.5 its normal size and remained so for nearly three days. The site of the bite was reported to itch. Dring (1979) collected an individual from a spiny palm in hillside forest 79om on Gunung Lawit. Grismer (2011b) reported this species from lowland forests usually 1-3 $\mathrm{m}$ off the ground in vegetation or on the forest floor.

\section{Boiga jaspidea (Duméril, Bibron \& Duméril, 1854)}

(Figure 31)

Lata Belatan: LSUHC 10977 (USMHC 1210), 10 July 2012.

A male adult agrees with Tweedie's (1983) diagnosis in having a reddish-brown body with an irregular pattern of black and pinkish markings and a series of closely spaced black and white spots low down on each side; 209-290 ventral scale; no loreal pit or anterior poison fangs; round pupils; mid-body scales in 19-27 rows; single anal shield; ventrals clearly differentiated throughout the length of body; and tail round in cross section.

This specimen was found during the day coiled up on a palm leaf about a foot off the ground beside a forest trail.

\section{Dendrelaphis cyanochloris (Wall, 1921)}

Between camp and peak on Gunung Tebu: LSUHC 11229, 2 July 2013.

A subadult male (SVL $474 \mathrm{~mm}$ ) matches Vogel's (1990) diagnosis of specimen from Thailand, Vogel and van Rooijen's (2011) diagnosis of Dendrelaphis; Vogel, van Rooijen, and Hauser's (2012) diagnosis of Drendrelaphis, Tweedie's (1983) diagnosis, and Grismer's (2011a) diagnosis of specimen from the Seribuat Archipelago in having a long, thin body with a slightly enlarged rectangular head; head scales large and plate like; eyes large; pupil round; 15 rows of smooth, dorsal scales at mid-body, vertebral row enlarged; 167-181 keeled and laterally notched ventrals; 140-154 divided and keeled but not laterally notched subcaudals; divided anal plate; bronze top of head; body and neck blue-green; vertebral region brown; tail not striped; blue spots visible on the bases of the body scales when body inflates; and tail not banded. This specimen lacks the white pre orbital markings usually present in this species.

We collected the specimen while it was sleeping 3 $\mathrm{m}$ up in a tree along the trail. Vogel and van Rooijen (2012) and Vogel et al. (2012) noted that this species is often confused with $D$. nigroserratus from southern Myanmar and D. andamanensis from the Andaman Islands. Grismer (2011a) had similar observations of Dendrelaphis cyanochloris and noted that this species is common in streamside environments in both lowland and hill forest.

\section{Dendrelaphis formosus (Tweedie, 1983)}

Lata Tembaka: LSUHC 9892, 7 September 2010.

A single adult female specimen (SVL $682 \mathrm{~mm}$ ) is in accord with Vogel's (1990) diagnosis of specimen from Thailand and Tweedie's (1983) diagnosis in having a tail slightly compressed from side to side; ventral scales clearly differentiated throughout the length of the body; scales in 13-29 rows; double anal shield divided; scales at mid-body in 13-18 rows; number of scale-rows odd, 15, including a vertebral row; vertebral scales larger than the other dorsals; and pupils round.

The individual was collected at night while sleeping 3 $\mathrm{m}$ up in a tree.

\section{Lycodon subcinctus (Boie, 1827) (Figure 32)}

Lata Belatan: LSUHC 10910, 3 September 2012.

An adult male (SVL $52 \mathrm{~mm}$ ) agrees with Tweedie's (1983) diagnosis by lacking a preocular scale, having contact between prefrontal and loreal touch the eye; divided anal plate; large teeth, the anterior ones of the upper jaw the largest; supralabials $3-5$ touching the eye; 8 supralabials; ventral scales in 17 rows; ventrals not keeled or notched; 15 or 17 scale rows at midbody; anal shield divided; head squarish to rectangular, top usually bearing symmetrically arranged shields; three shields lying on a line between the eyes; body and tail round in cross-section.

This specimen was collected from inside a hole 1 meter above the ground at night. This species is commonly seen 


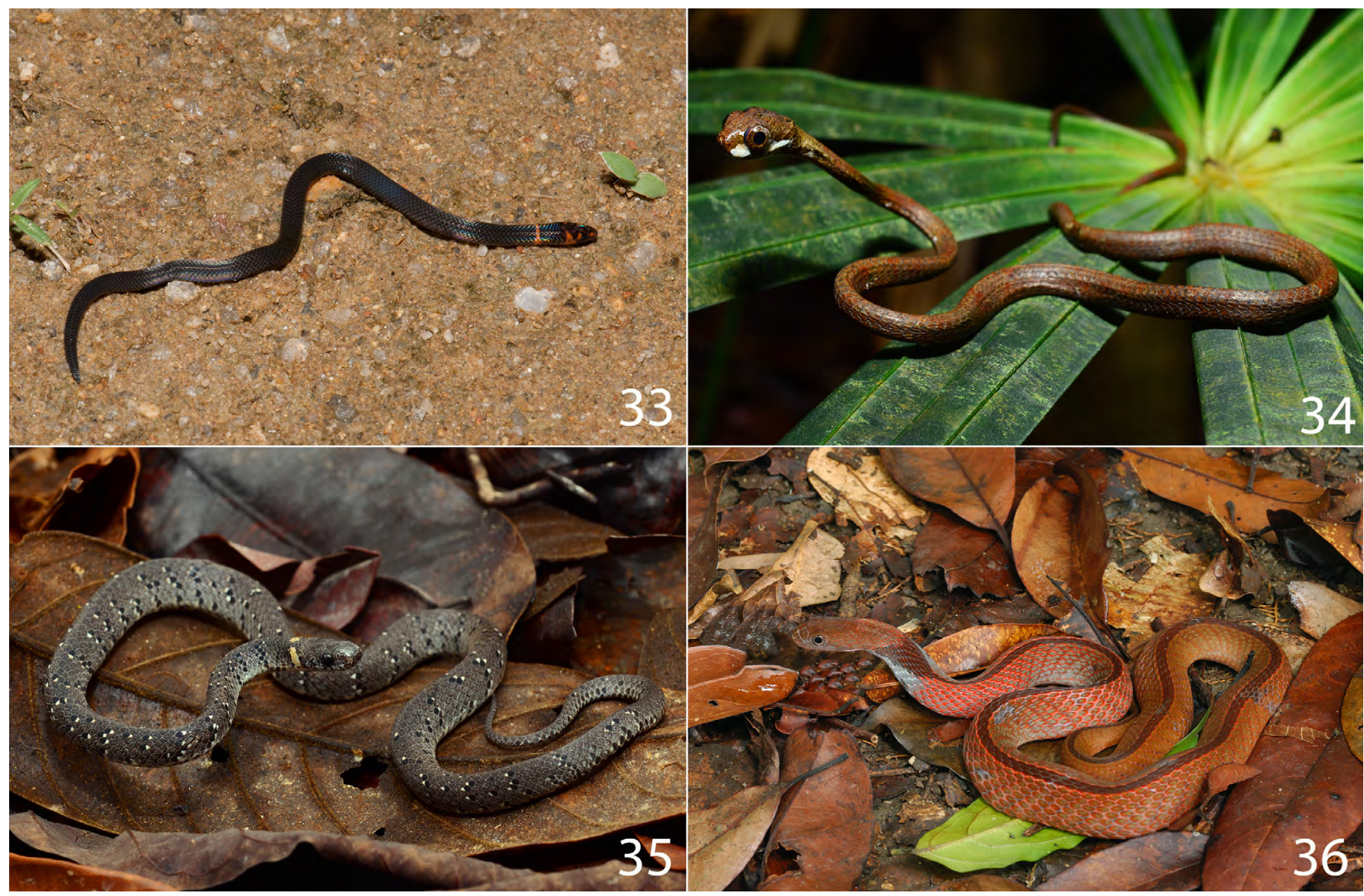

Figures 33-36: Snakes from Gunung Tebu, Lata Belatan, and Lata Tembaka. 33: Pseudorabdion sp. from Gunung Tebu. 34: Aplopeltura boa from Gunung Tebu. 35: Pareas margharitaphorus from Lata Belatan. 36: Macropisthodon rhodomelas from Lata Tembaka.

in both primary forests and anthropomorphic settings.

\section{Pseudorhabdion cf. longiceps (Figure 33)}

$300 \mathrm{~m}$ on Gunung Tebu: LSUHC 10905, 3 September 2012.

Genetic and morphological analysis indicates that this male specimen (SVL $83 \mathrm{~mm}$ ) is most likely a new species (Quah et al. in prep.)

LSUHC 10905 was collected during the morning hours at approximately $400 \mathrm{~m}$ in elevation while it was crossing the trail in hill dipterocarp forest.

\section{Family Pareatidae}

\section{Aplopeltura boa (Boie, 1828) (Figure 34)}

600-750 $\mathrm{m}$ on Gunung Tebu: LSUHC 10850, 1 September 2012.

A single hatchling (SVL $180 \mathrm{~mm}$ ) agrees with Tweedie's (1983) diagnosis in having a round tail in cross-section; ventrals differentiated throughout the length of the body; scales at mid-body in 13 rows; head square and covered on top with symmetrically arranged shields; always three shields lie on a line between the eyes; vertebral scales larger than the other dorsals; subcaudals single; and no median groove under the chin.

The specimen was found on a leaf at night.
Pareas margaritophorus (Jan, 1866) (Figure 35)

Lata Belatan: LSUHC 10980 (USMHC 1127), USMHC 1128, 9 July 2012.

Both male male specimens mostly agree with Tweedie's (1983) diagnosis of Peninsular Malaysian specimen in having one loreal scale on each side and preocular scales; labials separated from the eye by one or more subocular scales; vertebrals not enlarged and smooth; no median groove under the chin; subcaudals paired; scales in 15 rows at midbody; anal shields entire; head squarish to rectangular in shape, usually covered on top with symmetrically arranged shields; always three shields lie on a line between the eyes; ventrals clearly differentiated throughout the length of the body; and tail round in cross section. Although Tweedie (1983) noted a red band on the nape as a diagnostic character of this species, the band is often white.

Both specimens were collected at night when they were crawling across roads after a heavy rainstorm in the late evening.

\section{Family Homalopsidae}

\section{Hypsiscopus plumbea (Boie, 1827)}

Lata Belatan: LSUHC 10831, 31 August 2012. USMHC 1057, 10 July 2012. 
Both juveniles (SVL $129-187 \mathrm{~mm}$ ) is in accord with Grismer's (2011a) diagnosis of specimens of this species formerly recognized as Enhydris plumbea from the Seribuat Archipelago in having a short, heavy body with a flattened head and broadly rounded snout; head scales large and plate-like; eyes situated dorsally; pupils round; 19 rows of smooth dorsal scales at midbody; ventrals 112-139; 22-45 divided subcaudals; anal plate divided; head and body olive to brownish green; belly yellowish with black, medial spots; black and subcaudal stripe present. Following recent revision of the family by Murphy \& Voris (2014), this species has relocated to the genus Hypsiscopus.

In accordance with Tweedie (1983) the specimens are identified as $H$. plumbea by having 19 mid-dorsal scale rows.and this character differentiates them from other species formerly recognized as members of the genus Enhydris in Peninsular Malaysia; namely Subsessor bocourti, Enhydris enhydris, Kualatahan pahangensis and Phytolopsis punctate. A single internasal distinguishes $H$. plumbea from Raclitia indica that has two internasals.

Both specimens were collected at night around 8.3opm partially buried in the debris at the bottom of a shallow muddy pool with only their head sticking out to the surface along trail near at Lata Belatan behind the visitors' chalets.

\section{Family Natricidae}

Macropisthodon rhodomelas (Boie, 1827) (Figure 36) Lata Tembaka: LSUHC 8838, 13 March 2008.

An adult female (SVL $444 \mathrm{~mm}$ ) matches Tweedie's (1983) diagnosis in having the sixth upper labial scale not touching the eye; eyes not too large; and a brown to red body with a black vertebral strip which expands into a V-shaped blotch on the nape.

The specimen was collected during the morning while it crossing the road in a rubber plantation.

\section{Family Elapidae}

\section{Calliophis bivirgata (Boie, 1827)}

Lata Belatan, 3 July 2013.

One large individual was spotted crossing the trail near a river and escaped into thick, low vegetation. It had the distinctive orange head and tail and cyan-colored lateral stripes. This record is considered unconfirmed until a voucher photograph or specimen can be obtained.

\section{Family Viperidae}

Parias hageni (Lidthe de Jeude, 1886) (Figure 37) Lata Tembaka: LSUHC 9930, 7 September 2010.

A juvenile female (SVL $484 \mathrm{~mm}$ ) agrees mostly with Tweedie's (1983) diagnosis for Malaysian specimen in

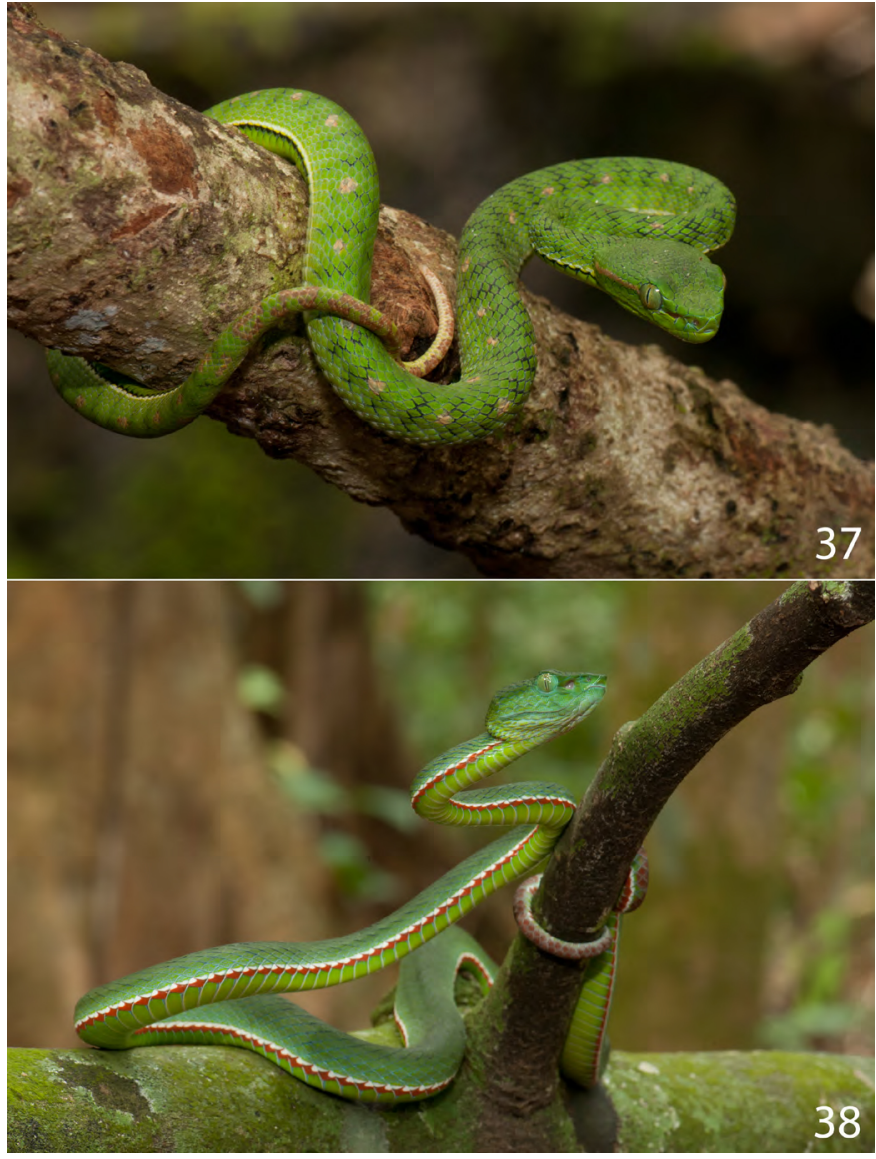

Figures 37 and 38: Snakes from Lata Tembaka and Gunung Tebu. 37: Pareas hageni from Lata Tembaka. 38: Popeia fucata from Gunung Tebu.

having a green body with two rows of pinkish spots and a white line along the lowest dorsals bordered below with black; supraocular scales broad, separated by 4-9 scales; 177-198 ventral scales; scales between the eyes bluntly keeled; head broad and flat; ventral scales differentiated; and tail rounded in cross section. This specimen disagrees with Tweedie's (1983) diagnosis by having nasal scales not in contact.

This specimen was found at night on a tree branch $3 \mathrm{~m}$ above the ground in front of a chalet.

Popeia fucata (Vogel, David, \& Pauwels, 2004)

(Figure 38)

Over 800 meters on Gunung Tebu: LSUHC 10911, 2 September 2012.

An adult male (SVL $439 \mathrm{~mm}$ ) agrees with Vogel et al.'s (2004) diagnosis of specimen from Malaysia and Thailand and Tweedie's (1983) diagnosis by having the tail round in cross-section; ventrals clearly differentiated throughout the length of the body; scales at mid-body in 19-21 rows; head broad and flat, covered with small irregularly arranged scales; supra-ocular scales narrow or indistinct, separated across the head by 8-13 scales; and 150-175 ventral scales. Vogel et al. (2004) observed that individuals from Thailand have greenish-gray tails, heavily mottled with large, irregular rusty-brown 

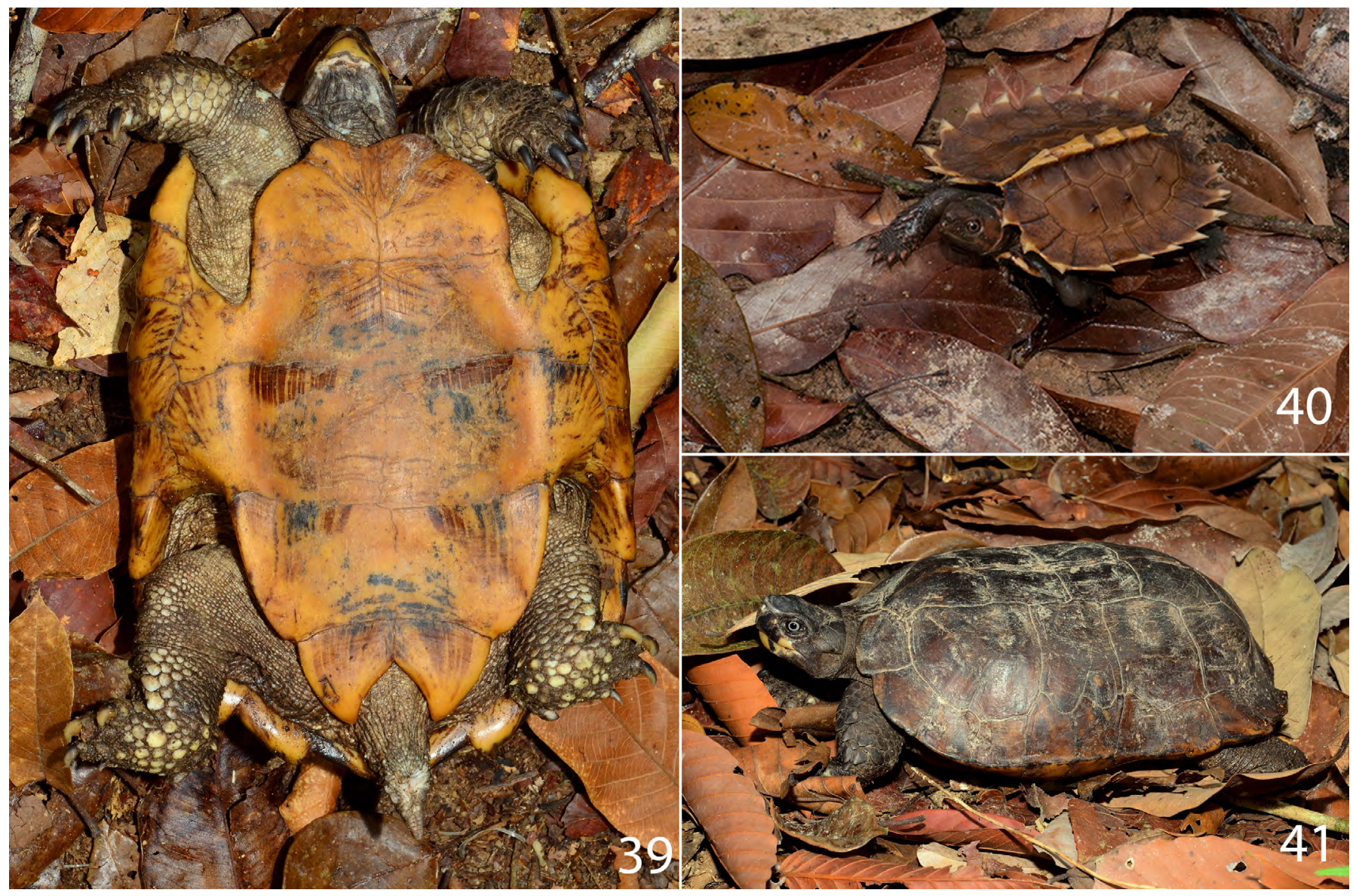

Figures 39-41. Heosemys spinosa from Lata Belatan. 39: Plasteron. 40: Juvenile. 41: Adult.

blotches on its sides in its anterior part, becoming posteriorly nearly completely rusty brown with darker hues and white whereas specimens from central West Malaysia have the tail green laterally, rusty dark brown or dark above, with a sharp border between green and brown areas. The Gunung Tebu specimen may be a new species (Quah in prep).

LSUHC 10911 was collected at night from 3 meters up a tree. Dring (1979) listed this species as Trimeresurus popeorum and collected specimen from vegetration along streams during night and day at $790 \mathrm{~m}$ on Gunung Lawit. Based on Vogel et al. (2004), T. popeorum is now restricted to Eastern India, Myanmar, Northern Thailand and Laos. Populations in the Malay Peninsula excluding $P$. nebularis from Cameron Highlands are recognized as $P$. fucata.

\section{Tropidolaemus wagleri (Wagler, 1830)}

Lata Tembaka: LSUHC 9916, 7 September 2010.

An subadult male matches Tweedie's (1983) diagnosis in having a tail slightly laterally compressed; dorsal scales in 13-29 rows at midbody; head broad and flat, covered on top with small scales on top of its head; scales on tope of the head, between the eyes, strongly keeled; and body green with small red and white spots.

LSUHC 9916 was collected at night from $5 \mathrm{~m}$ up in stalks of bamboo. Grismer (2011a) had similar observations.

\section{Turtles Family Geomydidae}

Heosemys spinosa (Gray, 1830) (Figure 39-41)

Lata Belatan, 11 July 2012. Gunung Lawit, 23 June 2012. An adult male was found at Lata Belatan in the late evening along the same stretch of swamp as Enhydris plumbea. It was identified based on the elongated and flat carapace with a prominent raised keel running along the center of each vertebral scute. The plastron was strongly concaved with a faded pattern of radiating lines that has resulted in an almost uniform yellow plastron that has been noted by Auliya (2007) for this species. A juvenile individual was found along the trail during the afternoon at Gunung Lawit.

We report 50 species of frogs from 20 genera and six families, 35 species of lizards from 19 genera and four families, 18 species of snakes from 12 genera and six families, and three species of turtle from three genera and three families (Table 1). Thirteen species of frogs (Fejervarya limnocharis, Kalophrynus pleurostigma, Phrynoides aspera, Taylorana hascheanus, Occidozyga martensi, Odorrana hosii, Microhyla bearmorei, M. fissipes, M. heymonsi, $M$. superciliaris, Polypedates leucomystax, $P$. macrotis, Kurixalus appendiculatus), 12 species of lizards (Aphaniotis fuscus, Calotes emma, C. versicolor, Draco 
melanopogon, D. sumatranus, Gehyra mutilata, Gekko monarchus, Hemidactylus craspedotus, Ptychozoon kuhlii, Dasia olivacea, Eutropis macularia, Varanus nebulosus) and five species of snakes (Boiga drapezii, Hypsiscopus plumbea, Lycodon subcinctus, Macropisthodon rhodomelas, Pareas hageni.) are common to anthropomorphic areas of Lata Belatan and Lata Tembaka. Of the 50 species of frogs collected, Ansoina latifii, A. lumut, Duttaphrynus melanostictus, Hylarana labialis, $H$. picturata, Leptobrachium hendricksoni, Leptolalax sp. nov., Megophrys nasuta, Microhyla fissipes, M. supercilaris, Occidozyga martensii, Odoranna hosii, Philautus petersi, and Taylorana hascheanus are new records for this portion of Peninsular Malaysia. We report that Aplopeltura boa, Boiga jaspidea, Calliophis bivirgata, Dendrelaphis cyanochloris, D. formosus, Hypsiscopus plumbea, Lycodon subcinctus, Macropisthodon rhodomelas, Pareas margaritophorus, Parias hageni, Popeia fucata, and Tropidolaemus wagleri are new records of snakes. Calotes emma, C. versicolor, Cyrtodactylus tebuensis, C. timur, Dasia olivacea, Draco sumatranus, D. quinquefasciatus, Eutropis macularia, Gekko monarchus, G. smithii, Hemidactylus craspedotus, $H$. platyurus, Hemiphyllodactylus tehtarik, Lipinia vittigera, Ptychozoon kuhli, and Varanus nebulosus are new records of lizards. Heosemys spinosa is a new record for Lata Belatan and Gunung Lawit.

Scheffers et al. (2013) identified arborality (vertical stratification) as a key determinant of rainforests species richness and abundance patterns in Mount Banahaw, Phillipines and Singaporean lowlands especially for ectothermic and hydrophilic species such as frogs. They indicated that arboreal frog richness peaked between $600 \mathrm{~m}$ and $800 \mathrm{~m}$ and that increased elevation resulted in increased vertical species stratification. Although we only found three arboreal frog species out of nine species collected between $600 \mathrm{~m}$ and $800 \mathrm{~m}$ on Gunung Tebu, the overall frog and lizard richness for both arboreal and ground-dwelling assemblages did peak between $600 \mathrm{~m}$ and $750 \mathrm{~m}$ on Gunung Tebu with most of our collections being made near the Punca Air (610 $\mathrm{m})$. This includes nine of the 12 frog species and eight of the 10 lizard species collected from Gunung Tebu. We can infer from our results that $600-750 \mathrm{~m}$ on Gunung Tebu is an ideal climate for the majority of the species collected. It is possible that climate change could cause a shift in this altitudinal distribution and Scheffers et al. (2013) suggested that global warming could cause arboreal species to migrate downslope to cooler and wetter ground creating a "flattening" effect in their stratification. Flattening could seriously alter the forest ecosystem and impact the survival of numerous species (Scheffers et al. 2013). It is imperative to consider that our study did not focus specifically on frog arborality like Scheffers et al. (2013). Therefore we cannot rule out the possibility that frog arborality peaked between
500-800 $\mathrm{m}$ and future studies are required to determine this. Such studies would shed light on niche partitioning and species distribution patterns across mountain ecosystems in Peninsular Malaysia. They would also be tremendously vital to understaning the impact of climate change on Peninsular Malaysia's montane rainforest ecosystems.

The records provided here contribute to a growing body of knowledge about the herpetofauna of northeastern Peninsular Malaysian herpetology, highlighting the immense biodiversity of this area. Gunung Lawit was the type locality for rare species including Psuedocalotes dringi, Cyrtodactylus elok, and Cnemaspis argus. Until our return, this region was unexplored by science since Dring's 1979 survey and now we are discovering several new species at these mountains and surrounding areas: Microhyla mantheyi Das, Yaakob \& Sukumaran (2007), Ansonia latifii Wood, Grismer, Norhayati, \& Juliana, (2008), Rhacophorus norhayati Chan \& Grismer (2010), Cyrtodactylustebuensis Grismer etal. (2012), Cyrtodactylus timur Grismer et al. (2013), Hemiphyllodactylus tehtarik Grismer et al. (2013), Ansonia lumut Chan et al. (2014), Leptolalax sp. nov. (Chan in prep), and Pseudorabdion cf. longiceps (Quah et al. in prep).

Southeast Asia contains $20-25 \%$ of the world's biodiversity while covering only $4 \%$ of its landmass (Meyers et al. 2000; Mittermeier et al. 2005; Corlett 2009a). However, without a substantial increase in biodiversity publications, the region could continue down a vortex of deforestation and species extinction. Sodhi et al. (2004) reported that Southeast Asia has the highest relative rate of deforestation among all of the world's major tropical regions and they predicted that it could lose up to three-quarters of original rainforests by 2100 along with $42 \%$ of its biodiversity. Biodiversity studies provide the knowledge to prioritize conservation areas and habitats, and to model sustainable use of resources (Sodhi et al. 2004). Therefore, they are extremely vital to the health of Peninsular Malaysian biodiversity and especially for that of the entirety of Southeast Asia. Future surveys of ecosystems less explored by science, such as upper montane rainforest, limestone karst, and mangrove swamps, would be tremendous driving forces towards increased Malaysian and Southeast Asian biodiversity conservation.

\section{ACKNOWLEDGEMENTS}

We thank the many La Sierra University and Malaysian students who assisted in collecting and prepping specimens in the field. In particular, we thank Heather Heinz, Ariel I. Loredo, and Anthony Cobos. We also thank the East Texas Herpetological Society for providing grant money to fund this research. All permits and collecting permissions were issued by the Forestry Department of Terengganu and the Forestry 
Department of Peninsular Malaysia. This trip was partially funded by the La Sierra University College of Arts and Sciences.

\section{LITERATURE CITED}

Auliya, M. 2007. An identification guide to the tortoises and freshwater turtles of Brunei Darussalam, Indonesia, Malaysia, Papua New Guinea, Philippines, Singapore and Timor Leste. Malaysia: TRAFFIC Southeast Asia. 99 pp.

Berry, P.Y. 1975. The amphibian fauna of Peninsular Malaysia. Kuala Lumpur: Tropical Press. 127 pp.

Boulenger, G.A. 1900a. Descriptions of new batrachians and reptiles from Larut Hills, Perak. The Annals and Magazine of Natural History 6: 186-193. http://www.biodiversitylibrary.org/ page/15629643

Boulenger, G.A. 19oob. Descriptions of new reptiles from Perak, Malay Peninsula. The Annals and Magazine of Natural History 5: 306-308. http://www.biodiversitylibrary.org/page/16333723

Boulenger, G.A. 1903. Report on the batrachians and reptiles; pp. 131-176, in: Fasciculi Malayenses. Anthropological zoological results of an expedition to Perak and the Siamese Malay states 1901 - 1902, undertaken by Nelson Annandale and Herbert C. Robinson. Vol. 1, Zoology. Liverpool: Liverpool University Press.

Boulenger, G.A. 1908. Report on the Gunung Tahan Expedition, May-Sept. 1905. III. Fishes, batrachians, and reptiles. Journal of the Federal States of Malaya 3: 61-69.

Chan, K.O., L.L. Grismer, A. Norhyati and D. Belabut. 2009a. A new species of Gastrophrynoides (Anura: Microhylidae): an addition to a previously monotypic genus and a new genus for Peninsular Malaysia. Zootaxa 2124: 63-68.

Chan, K.O., D. Belatbut and N. Ahmad. 2009b. A revised checklist of the amphibians of Peninsular Malaysia. Russian Journal of Herpetology 17 (3): 202-206.

Chan, K.O., L.L. Grismer, S. Anuar, E. Quah, M.A. Muin, A.E. Savage, J.L. Grismer, A. Norhayati, A-C. Remegio and L.F. Greer. 2010. A new endemic Rock Gecko Cnemaspis Strauch 1887 (Squamata: Gekkonidae) from Gunung Jerai, Kedah, northwestern Peninsular Malaysia. Zootaxa 2576: 59-68.

Chan, K.O., P.L. Wood. Jr., S. Anuar, M.A. Muin, E.S.H. Quah, A.X. Sumarli and L.L. Grismer. 2014. A new species of upland Stream Toad of the genus Ansonia Stoliczka, 1870 (Anura: Bufonidae) from northeasten Peninsular Malaysia. Zootaxa 3764 (4): 427440. doi: 10.11646/zootaxa.3764.4.3

Corlett, R.T. 2009. The ecology of tropical East Asia. Oxford University Press, Oxford. 272 pp.

Das, I. and Y. Norsham. 2003. A new species of Dibamus (Squamata: Dibamidae) from Peninsular Malaysia. Raffles Bulletin of Zoology 51: 137-141. doi: 10.1093/acprof:0so/9780199681341.001.0001

Das, I., Y. Norsham and B.L. Lim. 2004. A new species of Calluella Stoliczka, 1872 (Anura: Microhylidae) from Taman Negara, Pehang State, Peninsular Malaysia. Raffles Bulletin of Zoology 52: $257-260$.

Dring, J.C.M. 1979. Amphibians and reptiles from northern Trengganau, Malaysia, with descriptions of two new geckos: Cnemaspis and Cyrtodactylus. Bulletin of the British Museum of Natural History 34: 181-241. http://www. biodiversitylibrary. org/page/2262098

Flower, S.S. 1896. Notes on a second collection of batrachians made in the Malay Peninsula 1895-96, with a list of species recorded from that region. Proceedings of the Zoological Society of London 1896: 856-914.

Flower, S.S. 1899. Notes on a second colletion of reptiles made in the Malay Peninsula and Siam. Proceedings of the Zoological Society of London 1899: 600-696, 885-916. http://www. biodiversitylibrary.org/page/31572568
Grandison, A.G.C. 1972. The Gunong Benom Expedition 1967. 5. Reptiles and amphibians of Gunong Benom with a description of a new species of Macrocalamus. Bulletin of the British Museum of Natural History Zoology 23: 45-101. http://www. biodiversitylibrary.org/page/26496873

Grismer, L.L. 2006a. Amphibians and reptiles of the Tioman Archipelago, Malaysia. Kuala Lumpur: Forestry Department of Peninsular Malaysia. http://agris.upm.edu.my:8080/dspace/ handle/o/7403

Grismer, L.L. 2006b. A new species of Ansonia Stoliczka, 1872 (Anura: Bufonidae) from Central Peninsular Malaysia and a revised taxonomy for Ansonia from the Malay Peninsular. Zootaxa 1327: 1-21. http://biostor.org/reference/16919

Grismer, L.L. 2006c. Two new species of skinks (Genus Sphenomorphus Fitzinger 1843) from the Seribuat Archipelago, West Malaysia. Herpetological Natural History 9: 151-162.

Grismer, L.L. 2007. A new species of small montane forest floor skink (genus Sphenomorphus Fitzinger 1843) from southern peninsular Malaysia. Herpetologica 63: 544-551. doi: 10.1655/0018-0831 (2007)63[544:ANSOSM]2.0.CO;2

Grismer, L.L. 2008a. On the distribution and identification of Cyrtodactylus brevipalmattus Smith 1923 and Cyrtodactylus elok Dring 1979. Raffles Bulletin of Zoology 56: 177-179.

Grismer, L.L. 2008b. A new species of insular skink (Genus Sphenomorphus Fitzinger 1843) from the Langkawi Archipelago, Kedah, West Malaysia with the first report of the herpetofauna of Pulau Singa Besar and an updated checklist of the herpetofauna of Pulau Langkawi. Zootaxa 1691: 53-56.

Grismer, L.L. 2011a. Amphibians and reptiles of the Seribuat Archipelago. Franfurt am Main: Edition Chimaira. 239 pp.

Grismer, L.L. 2011b. Lizards of Peninsular Malaysia, Singapore and their adjacent archipelagos. Their Description, Distribution, and Natural History. Franfurt am Main: Edition Chimaira. 728 pp.

Grismer, L.L. and K.A. Pan. 2008. Diversity endemism and conservation of the amphibians and reptiles of southern Peninsular Malaysia and its offshore islands. Herpetological Review 3: 270-281.

Grismer, L.L. and K.O. Chan. 2010. Another new rock gecko (genus Cnemaspis Strauch 1887) from Pulau Langkawi, Kedah, Peninsular Malaysia. Zootaxa 2419: 51-62.

Grismer, L.L., J. Sukumaran, J.L. Grismer, T.M. Youmas, P.L. Wood Jr. and R. Johnson. 2006d. Report on the herpetofauna of the Temengor Forest Reserve, Perak, West Malaysia. Hamadryad 29: 15-32.

Grismer, L.L., J.L. Grismer and J.M. McGuire. 2006e. A new species of pitviper of the genus Popeia (Squamata: Viperidae) from Pulau Tioman, Pahang, West Malaysia. Zootaxa 1305: 1-19.

Grismer, L.L., J.L. Grismer, P.L. Wood Jr. and K.O. Chan. 20o8a. The distribution, taxonomy, and redescription of the geckos Cnemaspis affinis (Stoliczka 1887) and C. flavolineata (Nicholls 1949) with descriptions of a new montane species and two new lowland, karst-dwelling species from Peninsular Malaysia. Zootaxa 1931: 1-24.

Grismer, L.L., A. Norhayati, K.O. Chan, D. Belabut, M.A. Muin, P.L. Wood Jr. and J.L. Grismer. 2009a. Two new diminutive species of Cnemaspis Strauch 1887 (Squamata: Geckkonidae) from Peninsular Malaysia. Zootaxa 2019: 40-56.

Grismer, L.L., A. Norhayati and K.O. Chan. 2009b. A new diminutive, upland Sphenomorphus Fitzinger 1843 (Squamata: Scincidae) from the Belum-Temengor Forest Complex. Peninsular Malaysia. Zootaxa 2312: 27-38.

Grismer, L.L, K.O. Chan, J.L., Grismer, P.L. Wood Jr. and A. Norhayati. 2010. A checklist of the herpetofauna of the Banjaran Bintang, Peninsular Malaysia. Russian Journal of Herpetology 17: 147-160.

Grismer, L.L., E.S.H Quah, M.A. Muin, C.D. Siler, J.L. Grismer, K.O. Chan, P.L. Wood Jr., A.M. Shahrul and A. Norhayati. 2011. A new 
species of legless skink of the genus Larutia (Böhme) from Pulau Pinang, Peninsular Malaysia with a phylogeny of the genus. Zootaxa 2799: 29-40.

Grismer, L.L., P.L. Wood Jr., E.S.H. Quah, S. Anuar, M.A. Muin, M. Sumontha, A. Norhayati, A.M. Bauer, S. Wangkulangkul, J.L. Grismer and O.S.G. Pauwels. 2012. A phylogeny and taxonomy of the Thai-Malay Peninsula Bent-toed Geckos of the Cyrtodactylus pulchellus complex (Squamata: Gekkonidae): combined morphological and molecular analyses with descriptions of seven new species. Zootaxa 3520: 1-55.

Grismer, L.L., S. Anuar, M.A. Muin, E.S.H. Quah and P.L. Wood Jr. 2013a. Phylogenetic relationships and descriptions of a new upland species of Bent-toed Gecko (Cyrtodactylus Gray, 1827) of the $C$. sworderi complex from northeastern Peninsular Malaysia. Zootaxa 3616(3): 239-252. doi: 10.11646/zootaxa.3616.3.2

Grismer, L.L., P.L. Wood Jr., S. Anuar, M.A. Muin, E.S.H. Quah, J.A. McGuire, R.M. Brown, N.V. Tri and P.H. Thai. 2013b. Integrative taxonomy uncovers high levels of cryptic species diversity in Hemiphyllodactylus Bleeker, 1860 (Squamata: Gekkonidae) and the description of a new species from Peninsular Malaysia. Zoological Journal of the Linnean Society 169: 849-88o. doi: 10.1111/zoj.12064

Grismer, L.L., P.L. Wood Jr., S. Anuar, E.S.H. Quah, M.A. Abdul, M. Mohamed, K.O. Chan, A.X. Sumarli, A.I. Loredo and H.M. Heinz. 2014. The phylogenetic relationship of three new species of the Cyrtodactylus pulchellus complex (Squamata: Gekkonidae) from poorly explored regions in northeastern Peninsular Malaysia. Zootaxa 3764 (4): 427-440. doi: 10.11646/ zootaxa.3786.3.6

Grismer, L.L., P.L. Wood Jr., S. Anuar, E.S.H. Quah, M.A. Abdul, M.A. Muin, K.O. Chan, A.X. Sumarli and A.I. Loredo. [In press]. Repeated evolution of sympatric paleoendemic species in closely related, co-distributed lineages of Hemiphyllodactylus Bleeker, 186o (Squamata: Gekkonidae) across mountain tops in Peninsular Malaysia. Biological Society of the Linnean Society.

Hallermann, J. and J.A. McGuire. 2001. A new species of Pseudocalotes (Squamata: Agamidae) from Bukit Larut, West Malaysia. Herpetologica 57: 255-265. doi: 10.2307/3893094

Inger, R. F. 1966. The systematics and zoogeography of the Amphibia of Borneo. Fieldiana, Zoology 52: 1-402. doi: 10.5962/bhl title. 3147

Johnson, C.B., E.S.H. Quah, S. Anuar, M.A. Muin, P.L. Wood Jr., J.L. Grismer, L.F. Greer, K.O. Chan, A. Norhayati, A.M. Bauer and L.L. Grismer. 2012. Phylogeography, geographic variation, and taxonomy of the Bent-toed Gecko Cyrtodactylus quadrivirgatus Taylor, 1962 from Peninsular Malaysia with the description of a new swamp dwelling species. Zootaxa 3406: 39-58. doi: 10.11646/ zootaxa.3620.3.10

Laidlaw, F.F.19oo. On the frogs collected during the 'Skeat Expedition' to the Malay Peninsular, 1899-1900. Proceedings of the Zoological Society of London 1900: 833-890.

Laidlaw, F.F. 1901a. On a collection of snakes, crocodiles, and chelonians from the Malay Peninsula, made by members of the 'Skeat Expedition,' Proceedings of the Zoological Society of London 1900: 301-311. http://biodiversitylibrary.org/page/31889072

Laidlaw, F.F. 1901b. On a collection of lizards from the Malay Peninsula, made by members of the 'Skeat Expedition,' 1899 -1900," Proceedings of the Zoological Society of London 1901: 301-311. http://www.biodiversitylibrary.org/page/31591269

Leong, T.M and B.L. Lim. 2003a. A new species of Rama (Amphibia: Anura: Ranidae) from the highlands of the Malay Peninsula, with diagnostic larval descriptions. Raffles Bulletin of Zoology 51: 115-122.

Leong, T.M., M. Matsui, H.-S. Yong and A.A. Hamid. 2003b. Revalidation of Rana laterimaculata Barbour and Noble, 1916 from the synonymy of Rana baramica Boettger, 1901. Current Herpetology. Kyoto 22: 17-27. doi: 10.5358/hsj.22.17

Lim, K.K.P., T.M. Leong and B.L. Lim. 2002. Herpetofaunal records from Camercon Highlands, peninsular Malaysia. Journal of Wildlife Parks 20: 49-57.

Loredo, A.I., P.L. Wood Jr., E.S.H. Quah, S.H. Anuar, L. Greer, A. Norhayati and L.L. Grismer. 2013. Cryptic speciation within Asthenodipsas vertebralis (Boulenger, 1900) (Squamata: Pareatidae), the description of a new species from Peninsular Malaysia, and the resurrection of A. tropidonotus (Lidth de Jude, 1923) from Sumatra: an integrative taxonomic analysis. Zootaxa 3664: 505-524. doi: 10.11646/zootaxa.3664.4.5

Matsui, M., H. Ito, S. Tomohiko, H. Ota, S. Saidapur, W. Khonsue, T. Tanaka-Ueno and G.-f. Wu. 2005. Taxonomic relationships within the Pan-Oriental narrow-mouth toad Microhyla ornata as revealed by mtDNA analysis (Amphibia, Anura, Microhylidae). Zoological Science, Tokyo 22: 489-495.

Matsui, M. and I. Jaafar. 2006. A new cascade frog of subgenus Odorrana from Peninsular Malaysia. Zoological Science 64: 647-651. doi: $10.2108 / \mathrm{zsj} .23 .647$

McLeod, D.S. and A. Norhayati. 2007. A new species of Theloderma (Anura: Rhacophoridae.) form southern Thailand and peninsular Malaysia. Russian Journal of Herpetology 14(1): 65-72.

Mitttermeier, R.A., P.R. Gil, M. Hoffman, J. Pilgrim, T. Brooks, C.G. Mittermeier, J. Lamoreux and G.A.B. Da Fonseca. (2005) Hotspots revisited: earth's biologically richest and most endangered terrestrial ecoregions. Washington, D.C.: Conservation International. $392 \mathrm{pp}$.

Murphy, J. C. and H.K. Voris. 2014. A checklist and key to the homalopsid snakes (Reptilia, Squamata, Serpentes), with the description of new genera. Fieldiana, Life and Earth Sciences 8: 1-43. doi: 10.3158/2158-5520-14.8.1

Myers, N., R.A. Mittermeier, C.G. Mittermeier, G.A.B. Da Fonseca and J. Kent. 2000. Biodiversity hotspots for conservation priorities. Nature 403: 853-858. doi: http://dx.doi:10.1038/35002501

Norsham, Y. and B.L. Lim. 2002. A new species of mountain reed snake. Macrocalamus gentingensis, from Genting Highlands, Pahang, peninsular Malysia. Hamadryad 27: 83-89.

Parker, H. W. 1928. The brevicipitid frogs of the genus Microhyla. Annals and Magazine of Natural History, Series 10, 2: 473-499. doi: http://dx.doi.10.1080/00222932808672911

Parker, H.W. 1934. A monograph of the frogs of the family Microhylidae. London: Trustees of The British Museum. 208 pp. http://biodiversitylibrary.org/page/27554550

Sanders, K.L., A. Malthotra, A. Gumprecht, R.S. Thorpe and U. Kuch. 2004. Popeia inornata, a new species of pitviper from west Malaysia (Squamata: Viperidae: Crotalinae). Russian Journal of Herpetology 11(3): 163-176.

Scheffers, B.R., B.L. Phillips, W.F. Laurance, N.S. Sodhi, A. Diesmos and S.E. Williams. 2013. Increasing arboreality with altitude: a novel biogeographic dimension. Proceedings of the Royal British Society 280: 20131581. doi: 10.1098/rspb.2013.1581

Sly, G.R. 1976. New locality records for some peninsular Amphibia, Reptilia, and Mammalia. The Malayan Natural Journal 29: 155-157. http://agris.fao.org/aos/records/XB7806809

Smedley, N. 1931. Amphibians and reptiles from the Cameron Highlands, Malay Peninsular. Bulletin of the Raffles Museum 6: 105-123.

Smith, M.A. 1922. On a collection of reptiles and batrachians from the mountains of Pahang, Malay Peninsula. Journal of the Federal States of Malaya 10: 263-282. http://www.biodiversitylibrary. org/page/19064308

Smith, M.A. 1935. On a collection of reptiles and amphibians from Perak, Malay Peninsula. Bulletin of the Raffles Museum 10: 61-63.

Sohdi, N.S., L.P. Koh, B.W. Brook and P.K.L. Ng. 2004. Southeast 
Asian biodiversity: an impending disaster. Trends in Ecology and Evolution 19(12): 654-66o. doi: 10.1007/978-94-011-0958-1_5

Taylor, E. H. 1962. The Amphibian Fauna of Thailand. The University of Kansas Science Bulletin 53(8): 265-599. http://www. biodiversitylibrary.org/page/ 4379553

Tweedie, M.W.F. 1983. The snakes of Malaya. Singapore: Singapore National Printers. 167 pp.

Vogel G., P. David and O.S.G. Pauwels. 2004. A review of morphological variation in Trimeresurus popeiorum (Serpentes: Viperidae: Crotalinae) with the description of two new species. Zootaxa 727: 1-63.

Wood P.L., Jr., L.L. Grismer, A. Norhayati and A. Juliana. 2008. Two new species of torrent dwelling toads Ansonia Stoliczka 1872 (Anura: Bufonidae) from Peninsular Malaysia. Herpetologica 64: 321-340. doi: 10.1655/0018-0831(2006)62[466:ANSOAS]2.0.CO;2
Wood P.L., Jr., J.L. Grismer, L.L. Grismer, A. Norhayati, K.O. Chan and A.M. Bauer. 2009. Two new montane species of Acanthosaura Gray, 1831 (Squamata: Agamidae) from Peninsular Malaysia. Zootaxa 2012: 28-46.

Authors' contribution statement: AXS wrote the text, made the analysis, and collected data. LLG collected data and provided figures. SSA and MAM collected data and provided permits. ESHQ collected data and provided figures.

Received: 2 December 2014

Accepted: 4 May 2015

Academic editor: Perry Wood 